Acta Crystallographica Section B

Structural

Science

ISSN 0108-7681

\section{J. Hauck* and K. Mika}

Institut für Festkörperforschung, Forschungszentrum Jülich, D-52425 Jülich, Germany

Correspondence e-mail: j.hauck@fz-juelich.de

\title{
Architecture of crystal structures from square planes
}

The crystal structures of ordered b.c.c. (body-centered cubic), f.c.c. (face-centered cubic) or primitive cubic alloys $A_{x} B_{y}$ and related $\mathrm{NaCl}, \mathrm{ZnS}$ or $\mathrm{CaF}_{2}$ derivative structures are characterized by the self-coordination numbers $T_{1}, T_{2}$ of the $A$ atoms with $A$ atoms. Structures with identical $T_{1}$ and $T_{2}$ values for all $A$ atoms are at the corners of $T_{1}$ and $T_{2}$ structure maps, and can be analyzed for attractive or repulsive interactions of $A$ atoms. Most observed structures are at the borders of the structure map and can be obtained by $\sim 10$ different combinations of structural units. The different combination mechanisms explain e.g. the shear structures of $\mathrm{CuAu}$ II or $\mathrm{Nb}_{2} \mathrm{O}_{5}$ and the occurrence of vacancies in NaCl-related structures like $\mathrm{NbO}$.

\section{Introduction}

A large number of crystal structures can be described as ordered body-centered cubic (b.c.c.), face-centered cubic (f.c.c.) or primitive cubic (p.c.) compounds $A_{x} B_{y}$ or as $\mathrm{NaCl}$, $\mathrm{ZnS}$ or $\mathrm{CaF}_{2}$ derivative structures (Villars \& Calvert, 1986; Parthé et al., 1993) with a distribution of $A$ and $B$ atoms on different positions. The number of observed structures is small compared with the number of all possible structures, which is $2^{n-1}$ for a unit cell with $n$ possible positions of $A$ or $B$ atoms. All reduced unit cells of the b.c.c., f.c.c. and p.c. lattice with $n \leq 9$ atom positions were determined and the different structures selected numerically in the present investigation. The theoretical structures can be sorted for different aspects such as high symmetry, single coordination numbers or the extent to which Pauling's rules (Pauling, 1929) are obeyed. Pauling's rule of parsimony is particularly useful for the selection: 'The number of essentially different kinds of constituents in a crystal tends to be small'. The polyhedra circumscribed about all chemically identical atoms should, if possible, be chemically similar and similar in the nature of the sharing of corners, edges and faces with other polyhedra. This explanation is similar to the Wiener-Sohncke principle: 'Points are disposed around each point in the same way as around every other' (Wiener, 1863; Sohncke, 1879; Brunner, 1971). We have selected the self-coordination numbers (s-CN) of $A$ atoms with $A$ atoms as parameters to characterize these structures (\$2). Table 1 shows the maximum s-CN values $T_{i}^{\max }$ for coordination shells $i=1-10$ for a variety of structures, which can be obtained from the square lattice. The maximum values are reduced if some of these positions are occupied by $B$ atoms in $A_{x} B_{y}$ (Fig. 1). A large number of possible structures can be characterized by these $T_{i}$ values and homometric structures (structures with identical $T_{i}$ values, §3) can be
Received 1 May 1998 Accepted 27 April 2000
(C) 2000 International Union of Crystallography Printed in Great Britain - all rights reserved 
differentiated by different space groups. The $T_{i}$ values can be plotted in $T_{1}, T_{2}$ structure maps such as those shown in Fig. 2.

The large variety of orderings of atoms in $A_{x} B_{y}$ is characterized by the number of nearest, next-nearest and thirdnearest neighbors of $A$ atoms, $T_{1}, T_{2}$ and $T_{3}$, and the ratio of $A$ and $B$ atoms $y / x \geq 1$. The $T_{1} T_{2} T_{3} ; y / x$ values of the minority component $A$ are sufficient to characterize an undistorted structure. The self-coordination numbers $T_{1}, T_{2}$ and $T_{3}$ of the $A$ atoms with $A$ atoms in $A_{x} B_{y}$ compounds can be plotted to create a $T_{1}, T_{2}$ or $T_{1}, T_{2}, T_{3}$ structure map such as that shown in Fig. 2.

The numerical procedure to obtain a structure map will be outlined for a single square layer occupied by $A$ and $B$ atoms (Fig. 1a). The procedure contains the following steps:

(i) The unit cell of the square layer is increased by adding more squares and the corners of the squares occupied by $A$ and $B$ atoms (Fig. $1 b$ ).

(ii) The positions at the corners are occupied with $A$ atoms to a maximum of $50 \%$ at $y / x \geq 1$. The structures at higher $A$ content are identical by exchange of the $A$ and $B$ atoms.

(iii) The different crystal structures are characterized by the coordination of the $A$ atoms with other $A$ atoms in the first, second and third coordination shells $T_{1}, T_{2}$ and $T_{3}$, and the ratio $y / x$ of $B$ to $A$ atoms, e.g. the notation $204 ; 1$ is used for the structure with $T_{1}=2 A$ atoms at distance $a$, no $A$ atoms in the second coordination shell at distance $2^{1 / 2} a, T_{3}=4 A$ atoms at distance $2 a$ and $y / x=1 . T_{1}^{\max }=T_{2}^{\max }=T_{3}^{\max }=4$ are the maximum self-coordination numbers of the square layer. The coordination numbers of each shell are averaged for structures which have differently coordinated $A$ atoms, e.g. the 042,202 and 124 (twice) coordination numbers of the four $A$ atoms are averaged in the $123 ; 1$ structure.

(iv) The crystal structures characterized by the coordination numbers $T_{1}, T_{2}$ and $T_{3}$, and a fixed composition $y / x$ can be plotted as single points in a three-dimensional $T_{1}, T_{2}, T_{3}$ graph (\$3) or as a projection in the $T_{1}, T_{2}$ plane as shown in Figs. $1 b$ and 2. All structures with $y / x=1$ are found to fall within a triangle, with the three structures 4 4 4; (1), 204 ; 1 and 04 4; 1 at the corners. The structure 44 ; (1) with the composition given by (1) in brackets can only be obtained in the limit of very large unit cells, because the boundary line between the $A$ and $B$ clusters prevents an exact realisation $444 ; 1$ for finite cells. The 444 ; (1) values are also valid for an occupation of all sites by $A$ atoms.

(v) The structures with $y / x=1$ shown on the structure map can be considered as combinations of the variously shaded squares containing different numbers of $A$ atoms and different configurations (cis and trans) for the occupation of two positions (Fig. 1b). The 04 4; 1 and 204 ; 1 structures at the righthand and upper corners of the triangle (Figs. 1 and 2) consist of squares containing two $A$ atoms in opposite trans or neighboring cis configurations, respectively. The other structures at the right-hand side with the same composition as e.g. 1 2 3; 1 can be obtained by a combination of the two structural units of $044 ; 1$ and $204 ; 1$ (shown with different shading). The 44 4; (1) structure at the left-hand corner of the triangle can be considered as complete segregation of $A$ and $B$ atoms with
Table 1

Maximum self-coordination numbers (s-CN values) $T_{i}^{\max }$ and radii $R_{i}$ of shells in units of $a_{0} / 2\left(\mathrm{CaF}_{2}\right.$, perovskite series, face-centered cubic, bodycentered cubic lattice) or $a_{0}$ (square net) for the first to the tenth coordination of $A$ atoms with $A$ atoms $\left(A_{x} B_{y}\right), \mathrm{F}$ with $\mathrm{F}$ atoms $\left(\mathrm{CaF}_{2}\right)$ or $\mathrm{O}$ atoms with $\mathrm{O}$ atoms (perovskite series), respectively.

\begin{tabular}{|c|c|c|c|c|c|c|c|c|c|c|}
\hline \multirow[b]{2}{*}{$i$} & \multicolumn{2}{|c|}{ p.c. $/ \mathrm{CaF}_{2}$} & \multicolumn{2}{|c|}{ Perovskite } & \multicolumn{2}{|c|}{ f.c.c. } & \multicolumn{2}{|c|}{ b.c.c. } & \multicolumn{2}{|c|}{ Square } \\
\hline & $T_{i}$ & $R_{i}^{2}$ & $T_{i}$ & $R_{i}^{2}$ & $T_{i}$ & $R_{i}^{2}$ & $T_{i}$ & $R_{i}^{2}$ & $T_{i}$ & $R_{i}^{2}$ \\
\hline 1 & 6 & 1 & 4 & 1 & 12 & 2 & 8 & 3 & 4 & \\
\hline 2 & 12 & 2 & 8 & 2 & 6 & 4 & 6 & 4 & 4 & \\
\hline 3 & 8 & 3 & 8 & 3 & 24 & 6 & 12 & 8 & 4 & \\
\hline 4 & 6 & 4 & 6 & 4 & 12 & 8 & 24 & 11 & 8 & \\
\hline 5 & 24 & 5 & 16 & 5 & 24 & 10 & 8 & 12 & 4 & \\
\hline 6 & 24 & 6 & 16 & 6 & 8 & 12 & 6 & 16 & 4 & \\
\hline 7 & 12 & 8 & 12 & 8 & 48 & 14 & 24 & 19 & 8 & 10 \\
\hline 8 & 30 & 9 & 20 & 9 & 6 & 16 & 24 & 20 & 8 & 13 \\
\hline 9 & 24 & 10 & 16 & 10 & 36 & 18 & 24 & 24 & 4 & 16 \\
\hline 10 & 24 & 11 & 24 & 11 & 24 & 20 & 32 & 27 & 8 & 17 \\
\hline
\end{tabular}

complete occupancy of the squares by $A$ or $B$ atoms, respectively. These structural units can be combined with squares containing two $A$ atoms in a cis configuration to the structures at the left-hand border of the triangle. Points within the triangle are obtained by the combination of all structural units.

(vi) The s-CN values $T_{i}^{A}$ and $T_{i}^{B}$ of $A$ and $B$ atoms are different for $y / x>1$. The s-CN values of the minority component $A$ are plotted in Fig. 2 for $A_{x} B_{y}, y / x \geq 1$. The lefthand border of the structure map is common for all values of $y / x$, whereas the right-hand border is different for different $y / x$ values, as indicated by a broken line for $y / x=2$ in Fig. 2. An alternative way of representing the structure diagram is to use the Cowley-Warren short-range order parameter $\alpha_{i}$ (Hauck, 1980), as defined in (1) and (2) below. This can have values $-1 \leq \alpha_{i} \leq 1$ and can be obtained from the self-coordination numbers (s-CN) $T_{i}^{A}$ and $T_{i}^{B}$ of $A$ and $B$ atoms or from the $T_{i}^{A}$ and $y / x$ values (Hauck $\&$ Mika, 1994) by means of (1)-(6).

$$
\begin{gathered}
\alpha_{i}=1-p_{i}^{B} / y^{\prime}, \\
y^{\prime}=y /(x+y), \\
T_{i}^{B}=T_{i}^{\max }-\left(T_{i}^{\max }-T_{i}^{A}\right) x / y, \\
\alpha_{i} T_{i}^{\max }=T_{i}^{A}+T_{i}^{B}-T_{i}^{\max }, \\
\alpha_{i} T_{i}^{\max }=T_{i}^{A}-\left(T_{i}^{\max }-T_{i}^{A}\right) x / y, \\
T_{i}^{\max }=T_{i}^{A}+T_{i}^{A B} .
\end{gathered}
$$

$p_{i}^{B}$ is the probability of finding a $B$ atom in the $i$ th coordination shell of an $A$ atom. $y^{\prime}$ is the fraction of $B$ atoms in $A_{x} B_{y}$ as given by (2). The coordination numbers $\mathrm{CN}=T_{i}^{A B}$ of $A$ atoms coordinated by $B$ atoms are related to $T_{i}^{A}$ by (6). Structures with compositions $y / x>1$ can be obtained by using other structural units. The $004 ; 3$ structure at the top-right corner of 
the structure map for $y / x=3$ (Fig. 2) contains only squares with single occupancy. The $202 ; 3$ structure contains squares with cis occupation or without $A$ atoms similar to that for $y / x=$ 1. The structures on the right-hand border as e.g. $022 ; 2$ can also be obtained by structural units similar to those for $y / x=1$, however, with different concentrations of units containing zero, single or double (trans) occupation.

The $202 ; 2,103 ; 2$ and $022 ; 2$ structures at the corners of the $y / x=2$ field each consist of a combination of two structural units only. Structures at the borders as e.g. $322 ; 2$ or inside the $y / x=2$ field contain three or more structural units, respectively.

(vii) The $\alpha_{i}$ values are zero for a random distribution of $A$ and $B$ atoms, because the mean value of $T_{i}^{A}+T_{i}^{B}$ equals $T_{i}^{\max }$, which corresponds e.g. to $T_{1}=T_{2}=T_{3}=2$ at composition $y / x=$

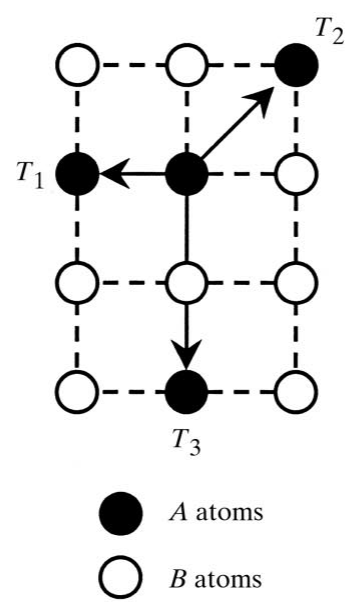

(a)
1 (Fig. 2). Very small $\alpha_{i}$ values are expected for $A_{x} B_{y}$ with very weak interactions between $A$ and $A$ or $B$ and $B$ atoms and in particular at high temperatures. Positive $\alpha_{1}$ values are obtained for attractive interactions of $A$ atoms, i.e. for cluster formation or segregation. The $202 ; 2$ and $322 ; 2$ structures of Fig. 1(b) consist of single and double rows of $A$ atoms, respectively. Proceeding down the left-hand border of the structure map (Fig. 2) corresponds to increasing size of the $A$ and $B$ clusters until complete segregation of $A$ and $B$ atoms occurring in the 444 ; (1) structure. Negative $\alpha_{1}$ values indicate repulsive interactions such as Coulomb repulsion between $A$ atoms.

(viii) Two-dimensional square structures are observed e.g. for gas molecules adsorbed on the (100) surfaces of b.c.c. metals (MacLaren et al., 1987). The extent of occupation of the surface of the metal atoms with gas molecules depends on the size of the gas molecules, the equilibrium gas pressure and the interaction between the molecules. The unit cell is usually described by the length of the two sides $l_{1} \times l_{2}$ relative to the underlying b.c.c. cell (Hauck \& Mika, 1994, 2000b; MacLaren et al., 1987). There are different structures with identical unit cells for the occupation of two or more positions, as can be seen by the two $2 \times 3$ structures $103 ; 2$ and $022 ; 2$ (Fig. 1b).

(ix) Other structures such as e.g. 004 ; 3 and 04 4; 1 at the right-hand border of the structure map have the same cell size, but different concentrations. An 00 4; 3 structure of metal atom $A$ can be combined with a second $004 ; 3$ structure of $A^{\prime}$ at the center to give $A A^{\prime} B_{2}$ or $A_{2} B_{2}$ with an $044 ; 1$ structure. This type of combination of structural units is quite frequent in ordered b.c.c., f.c.c. and p.c. alloys (\$\$3-5).

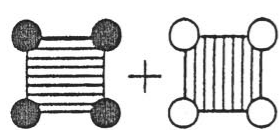

444;(1)

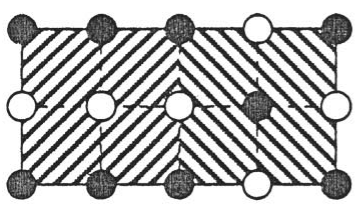

$123 ; 1$

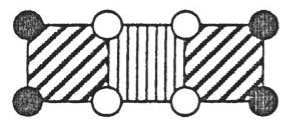

$202 ; 2$

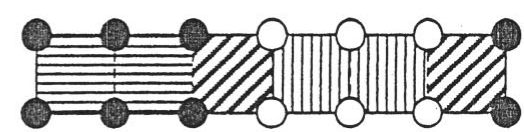

$3.32 .72 .7 ; 1$

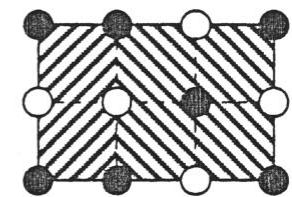

$0.72 .72 .7 ; 1$

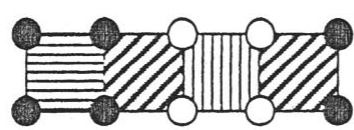

$322 ; 1$

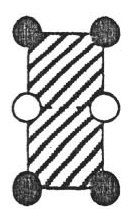

$204 ; 1$

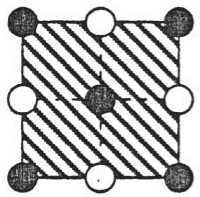

$044 ; 1$

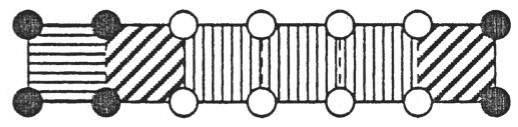

$322 ; 2$

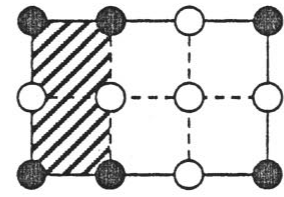

103;2

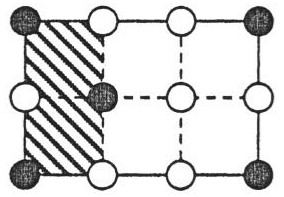

022; 2

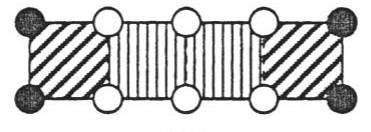

202;3

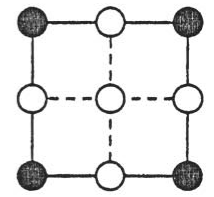

004;3

Figure 1

(b)

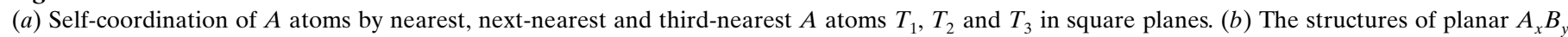
compounds denoted as $T_{1} T_{2} T_{3} ; y / x$ contain squares with $0-4 A$ atoms $(\bullet)$ with a different shading of these structural units. 
The most important structures at the corners of the structure map have a single set of $T_{i}$ values such as $204 ; 1,044 ; 1$ and $004 ; 3$ in Fig. 1(b). The structures at the corners and along borders of the triangular structure map (for $y / x=1$ ) can be analyzed for different interactions between $A$ atoms and a combination of structural units at the borders can be used to vary these interactions. The three corners of the structure map correspond to repulsive interactions between $A$ atoms (e.g. Coulomb repulsion) in opposite trans positions (0 4 4; 1 structure), attractive interactions (e.g. covalent bonding) for $A$ atoms in neighboring cis positions (2 04 ; 1 structure), and segregation of $A$ and $B$ atoms in 444 ; (1). Since in this case the crystal splits into all $A$ and all $B$ regions, the composition cannot be obtained for finite unit cells and is indicated by placing $y / x$ in parentheses [step (iv), Fig. 1b]. The observed structures found in more complex systems are those on the right-hand border and in particular the structures at the corners of the structure map (2 $04 ; 1,044 ; 1$ and 004 ; 3; Hauck \& Mika, 1994). The coordination number of the $A$ atoms by nearest neighbor $B$ atoms $\mathrm{CN}=4-T_{1}$ increases from 2 in 204 ; 1 to 4 in 044 ; 1 .

Pauling's rule of parsimony is obeyed for these structures: The number of essentially different kinds of constituents in a crystal tends to be small (Pauling, 1929, 1960; Burdett, 1995). Structures, in which all $A$ and all $B$ atoms have the same coordination sequence $\left(T_{i}\right)$, e.g. 20 4; 1 and 04 4; 1 in Fig. 1, are usually highly symmetric, whereas structures containing $A$ atoms with different environments, such as e.g. 123 ; 1 or 322 ; 1 in Fig. 1(b), are built from different structural units. The symmetry of these structures is usually lower because of the different symmetry of the structural units (Hauck \& Mika,

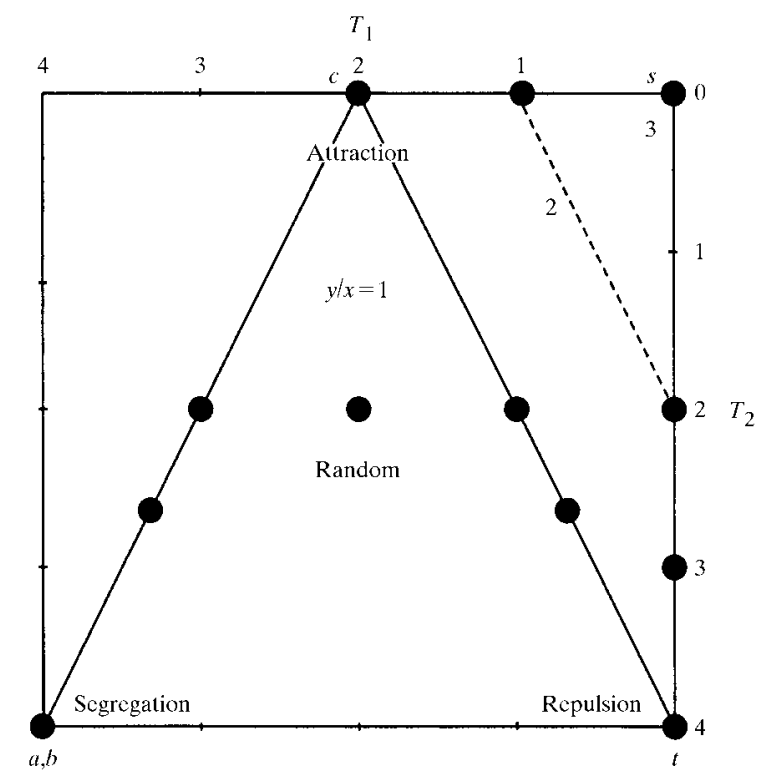

Figure 2

$T_{1}, T_{2}$ structure map of ordered $A_{x} B_{y}$ crystal structures $T_{1} T_{2} T_{3} ; y / x$ of square layers. The structures of Fig. $1(\bullet)$ are at the boundaries of the structure map, which vary at the right-hand side for different $y / x$. The $A$ atoms of the $A B$ alloys $(y / x=1)$ are segregated in $444 ;(1)$, attracted in 2 $04 ; 1$, repelled in $044 ; 1$, or random in $222 ; 1$.
1994). In most cases, the experimentally observed symmetry is identical with the symmetry determined for the undistorted lattice. Sometimes the symmetry is decreased because of the Jahn-Teller effect of transition metal $d$ electrons or because of a lone pair of main group elements such as $\mathrm{Bi}^{3+}$. The structures at the top and right-hand corners of the structure map also obey Pauling's electrovalence rule: The electrovalence of each $B$ atom in $A_{x} B_{y}$ should be compensated by the charge $q$ of the $z$ neighboring $A$ atoms with coordination number $\mathrm{CN}$ ( $\sum z q / \mathrm{CN}=$ charge of $B$ atoms; Pauling, 1929, 1960; Burdett, 1995). The 20 4; 1 and 04 4; 1 structures of Fig. 1 for oxide layers $A \mathrm{O}$ (i.e. $B=$ oxygen) with divalent $A$ atoms contribute the total electrovalence 2 to $\mathrm{O}$ atoms and compensate their formal charge -2 . On the other hand, one of the three different $\mathrm{O}$ atoms of the 123 ; 1 structure with electrovalencies 1.84, 2 and 2.33 does not obey Pauling's electrovalence rule within the allowed deviation of $\sim 1 / 6$ (1.83 - 2.17). Most electrovalencies of f.c.c., b.c.c. or p.c. structures of the righthand borders of the structure maps are within this limit (\$6).

The square-planar layers of Fig. 1(b) can be packed to give the body-centered cubic (b.c.c.) or face-centered cubic (f.c.c.) lattice with the lattice constants $a_{1}$ and $a_{2}$, respectively. The $A$ atoms in the center of the b.c.c. cell ( $\bullet$ in Fig. 3) have $T_{1}=8$ nearest neighbors at the distance $a_{1} 3^{1 / 2} / 2$ and $T_{2}=6$ secondnearest neighbors at the distance $a_{1}$. The self-coordination numbers $(\mathrm{s}-\mathrm{CN})$ of nearest neighbors $T_{1}$ increase from 8 in b.c.c. to 12 in the f.c.c. lattice (Table 1). Many $\mathrm{NaCl}, \mathrm{CaF}_{2}$ and $\mathrm{CaTiO}_{3}$ related structures can also be obtained from square layers with an ordering of $\mathrm{Cl}, \mathrm{F}$ or $\mathrm{O}$ atoms and vacancies. The $\mathrm{Cl}$ atoms of $\mathrm{NaCl}$ form an f.c.c. lattice and the $\mathrm{F}$ atoms of $\mathrm{CaF}_{2}$ a primitive cubic (p.c.) lattice. In $\mathrm{CaTiO}_{3}$ the two positions of the p.c. lattice ( $\circ$ in Fig. 3) are occupied by metal atoms such as $\mathrm{Ca}$ and $\mathrm{Ti}$ and three positions by vacancies. In $\mathrm{NaCl}$ four positions are occupied by $\mathrm{Na}$ atoms. Fig. 3 shows the $T_{i}$ values of $\mathrm{Cl}$ atoms in $\mathrm{NaCl}, \mathrm{F}$ atoms in $\mathrm{CaF}_{2}$ and $\mathrm{O}$ atoms and vacancies in the $\mathrm{CaTiO}_{3}$ series.

The metal atoms such as $\mathrm{Ca}$ and $\mathrm{Ti}$ of $\mathrm{CaTiO}_{3} \square_{3}$ and the interstitial $\mathrm{O}$ atoms and vacancies $\square$ at pseudo-octahedral sites [(6b) positions of $\operatorname{Im} \overline{3} \mathrm{~m}$ ] form together a primitive cubic structure with lattice constant $a_{0} / 2$ similar to the $\mathrm{F}$ atoms of $\mathrm{CaF}_{2}$ (Fig. 3). $\mathrm{CaTiO}_{3}$ and most superconducting oxides are in this group (Hauck \& Mika, 1997, 1998b; Hauck et al. 1999). The maximum s-CN values of the atoms lying on a p.c. lattice $\left(T_{1}=6, T_{2}=12, T_{3}=8\right)$ are decreased for $\mathrm{O}$ atoms in the $\mathrm{CaTiO}_{3}$ series $\left(T_{1}=4, T_{2}=8, T_{3}=8\right)$, because of the metal atoms (०) at two positions of the p.c. lattice.

Previous investigations (Hauck et al., 1988a,b, 1989; Hauck \& Mika, 1993, 1994) have shown that the structures are most likely to be found at the borders of the structure map. All $A$ (and all $B$ ) atoms of 8 b.c.c., 17 f.c.c. and 18 p.c. structures at the corners of the structure maps have the same set of $T_{i}$ values (single sets for $A$ and $B$ atoms, $M^{i}=2$ ), as was required by the Wiener-Sohncke principle. Four f.c.c. and four p.c. structures have identical $T_{1}$ and $T_{2}$ values. The remaining 20 b.c.c., 9 f.c.c. and 20 p.c. structures with the same sets of $T_{i}$ values for $A$ and $B$ atoms are not at the boundaries of the structure map $(\$ \$ 3-5)$. 


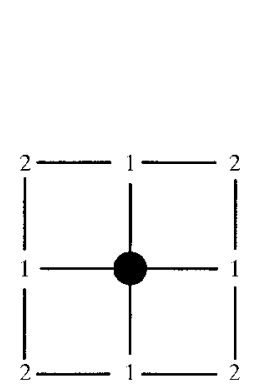

$T_{1}=4: T_{2}=4$

Square lattice

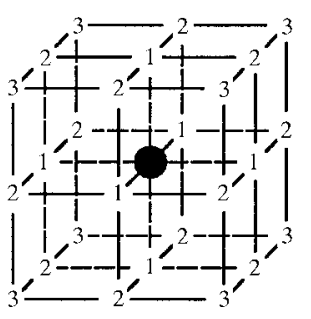

$T_{1}=4: T_{2}=12 ; T_{3}=8$ $\mathrm{F}$ in $\mathrm{Ca} \mathrm{F}_{2}$

Figure 3

Coordination polyhedra for the square, body-centered metal (b.c.c.), $\mathrm{NaCl}$ (f.c.c. lattice of $\mathrm{Cl}$ atoms), primitive cubic (p.c. F atoms in $\mathrm{CaF}_{2}$ ) and the $\mathrm{O}$ atom lattice in $\mathrm{CaTiO}_{3}$ and related structures with all possible sites for $\mathrm{O}$ atoms $[6(b)$ position of $\operatorname{Im} \overline{3} \mathrm{~m}$; perovskite series]. The central atom is shown by a filled circle (•) and the neighbors are shown by numbers with (1) for nearest, (2) for next-nearest and (3) for third-nearest neighbor positions. Some positions of the primitive cubic lattice are occupied by other atoms shown as open circles (o), e.g. $\mathrm{Na}$ in the $\mathrm{NaCl}$ and $\mathrm{Ca}, \mathrm{Ti}$ in the $\mathrm{CaTiO}_{3}$ derivative structures. Note that in $\mathrm{CaTiO}_{3}$ not all the neighboring sites are occupied by $\mathrm{O}$.

of different surroundings, as is required by Pauling's rule of parsimony. The structures can be assembled from structural units similar to a jigsaw puzzle. Most series of structures (structure families) can be described by a linear sequence of structural units. Therefore, the total number of structures at the borders of the structure maps is to a large extent limited. Up to four structural units labeled $a$ and $b$, for example, can be combined to the six sequences $a b, a_{2} b_{2}, a b_{2}, a b_{3}, a_{2} b$ and $a_{3} b$ (Hauck et al., 1999). The combination of structural units such as squares with two $A$ atoms in cis or trans configurations was outlined for the square-planar net (Fig. 1b).

The structure maps of b.c.c., f.c.c. and p.c. lattices will be analyzed in $\$ \S 3-$ 5 for $\sim 100$ structural units. Only a few structural units in about 10 different series of structures with varying degrees of repulsive (ionic) and attractive (covalent) bonding are observed. The correlation between distorted b.c.c. and f.c.c. alloys or $\mathrm{NaCl}, \mathrm{ZnS}$ and perovskite-related structures will be discussed in $\$ 6$. The close relation of structures obtained from square planes can also be visualized by many identical projection

Some of these structures were also obtained using different Ising methods such as Monte Carlo simulations (Ducastelle, 1991) by assuming different interaction energies $V_{i}^{A A}, V_{i}^{B B}$ and $V_{i}^{A B}$ between $A-A, B-B$ and $A-B$ bonds in the $i$ th shell $(\$ 2)$ or by the investigation of homogeneous sphere packing (Koch $\&$ Fischer, 1992). The ab initio crystal structure predictions by the Ising method are limited by the rapid increase in the values of $V_{i}$, where $V_{i}$ is the interaction constant of the $i$ th shell, with increased cluster size (Sanchez \& de Fontaine, 1981). The structures with the same $T_{i}$ values for all $A$ and $B$ atoms ( $(2)$ can be compared with homogeneous sphere packings, in which the $A$ or $B$ atom positions are vacant. The number of contacts between homogeneously packed spheres corresponds to the $T_{1}$ values of $A$ or $B$ atoms. In some cases $T_{1}$ will be zero and the number of contacts corresponds to the $T_{2}$ values. A small number of different types of homogeneous sphere packing, which is important for ordered b.c.c., f.c.c. and p.c. structures, is selected in the present investigation. These structures are shown on $T_{1}, T_{2}$ structure maps and the relationship between different structures is outlined for different structure families. Most observed structures (\$\$3-5) can be described by a combination of structural units such as the structures of the Ruddlesden-Popper structure family. The $T_{1}$ and $T_{2}$ values vary linearly at the borders of the structure map and the neighborhood of $A$ atoms changes gradually with a minimum patterns or identical space groups and Pearson symbols (\$6). Some structures can be considered as an intergrowth of b.c.c., f.c.c. and p.c. or $\mathrm{CaF}_{2}$ slabs (Parthé et al., 1993; Kripyakevich \& Grin, 1979; Pani \& Fornasini, 1990). Most of the slabs in these compounds with different ordering of metal atoms are very similar to the structural units of the present investigation.

\section{Ising-type analysis of structure families}

We have investigated the borders of structure maps for ordered b.c.c., f.c.c. and p.c. $A_{x} B_{y}$ structures with the following numerical procedure, similar to those outlined in previous investigations (Hauck et al., 1988b,c, 1989; Mika et al., 1989; Hauck \& Mika, 1993, 1994):

(a) Determination of all reduced unit cells (Křivý \& Gruber, 1976) with a maximum of nine sites for $A$ or $B$ atoms (Tables $1 \mathrm{~A}-3 \mathrm{~A}$ of deposited material ${ }^{\mathbf{1}}$ ). The lattice constants $a_{0}=2$ allow integer values for the cell parameters and $x, y, z$ coordinates of atoms.

(b) Occupation of sites in different concentrations and configurations.

\footnotetext{
${ }^{1}$ Supplementary data for this paper are available from the IUCr electronic archives (Reference: BR0078). Services for accessing these data are described at the back of the journal.
} 
(c) Selection of $A_{x} B_{y}$ structures $T_{1} T_{2} T_{3} ; y / x$ with identical s-CN values and composition $y / x$.

(d) Elimination of identical structures.

(e) Projection in different directions.

(f) Determination of the space group (Mika et al., 1994).

The $T_{1}, T_{2}$ and $T_{3}$ values were plotted for different $y / x$ values to create three-dimensional structure maps and the structures on the borders were analyzed for structural units (such as the squares with $A$ in cis and trans configurations in Fig. 1). The structures with larger unit cells could be constructed as soon as the structural units were known.

Some structures of the present compilation were obtained by a different method (Ising model), as will be outlined briefly in the following: At high temperatures many binary alloys $A_{x} B_{y}$ adopt a disordered form of one of the common crystal structures of metals: cubic close-packed (c.c.p.), hexagonal close-packed (h.c.p.) or body-centered cubic (b.c.c.). At lower temperatures the different metal atoms $A$ and $B$ order because of decreased entropy of mixing and increased attractive or repulsive interaction constants $\pm\left|V_{i}\right|$ in the $i$ th coordination shell, $i=1,2, \ldots$, where $V_{i}=V_{i}^{A A}+V_{i}^{B B}-2 V_{i}^{A B}$ is given by the interaction energies between $A-A, B-B$ and $A-B$ bonds in the $i$ th shell (Kanamori \& Kakehashi, 1977); $V_{i}>0$ favors $A-$ $B$ bonds, $V_{i}<0$ favors $A-A$ and $B-B$ bonds (Ducastelle, 1991; Allen \& Cahn, 1972). These authors have derived sets of ordered structures applying the Ising model with $V_{1}, V_{2}$ or ratios $V_{2} / V_{4}$ and $V_{3} / V_{4}$ as parameters.

An analysis of these $A_{x} B_{y}$ structures has shown that the $B$ atoms of many structures exhibit not a single coordination as the $A$ atoms do, but two to five different self-coordination numbers $T_{i}^{B}$ for different $B$ atoms in the same structure. In a few cases the different $T_{i}^{B}$ values start to deviate with a slightly different coordination only in a higher coordination shell, e.g. in the sixth coordination.

\section{Body-centered cubic alloys $A_{x} B_{y}$}

We have determined numerically the structures $A_{x} B_{y}$ with a single coordination $\left(M^{i}=2, \S 2\right)$ up to the 10 th shell of all $A$ and $B$ atoms with an upper bound of $x+y=9$ for b.c.c. structures. Of the 27 b.c.c. structures thus obtained (Table $2 a$, Fig. 1A, deposited), 10 b.c.c. structures were previously derived by the Ising model (Finel \& Ducastelle, 1984). These 10 structures are at the corners of the $T_{1} T_{2} T_{3} ; y / x$ structure map. Only the five ordered compounds 444 ; $1 \mathrm{a}(\gamma$-TiCu $), 40$ 12; 1 ( NaTl), 06 12; $1(\mathrm{CsCl}), 206 ; 2\left(\mathrm{CeCd}_{2}\right)$ and $044 ; 2$ $\left(\mathrm{MoSi}_{2}\right)$ are observed. Approximately 40 other observed structures (Table $2 b$, Fig.2A, deposited) are on the borders of the $T_{1}, T_{2}, T_{3}$ structure map (Fig. 4). The six structures with $y / x=1(0612 ; 1,246 ; 1,4012 ; 1,424 ; 1,444 ; 1,646 ; 1)$, and the 8612 ; (1) structure (corresponding to segregation of $A$ and $B$ atoms) are at the seven corners $(C)$ of a polyhedron in the $T_{1}, T_{2}, T_{3}$ coordinate system containing 15 edges $(E$; Hauck \& Mika, 1997). With Euler's formula $C+P=E+2$, topological consistency requires $P=10$ planes. The decahedron is projected as a triangle in the $T_{1}, T_{2}$ coordinate system (Fig. 4) with 06 12; 1 ( CsCl) (repulsion), 40 12; 1 ( NaTl) (attraction) and $8612 ;(1)$ (segregation) as corners. The other structures are inside the triangle (Fig. 4). Structures such as 23 12; (1) or 6312 ; (1) at the borders of the $T_{1}, T_{2}$ structure map (Fig. 4) can only be obtained as suprema in the limit of very large unit cells in a similar way to 8612 ; (1). The other structures along the edges of the $T_{1} T_{2} T_{3} ; y / x$ structure map allow the analysis of architecture by structural units. Figs. $1 \mathrm{~A}(a)-(d)$ (deposited) show most structures at the corners of the structure map projected in several different directions to illustrate the different structural units for structures on different edges of the $T_{1}, T_{2}, T_{3}$ structure map (Hauck \& Mika, 1997).

There are 10 b.c.c. homometric structures, as indicated by curly brackets in Table $2(a)$ - structures with an identical coordination (all $T_{i}$ ) of all atoms. The homometric crystal structures cannot be distinguished by powder patterns of $\mathrm{X}$ ray or neutron diffraction if the lattice is undistorted. They are labeled with $a$ and $b$ in Fig. 1A (deposited) and are bracketed in Tables 2-6. In other ('quasi-homometric') structures the $T_{i}^{B}$ values of the majority component $B$ deviate at higher coordination numbers as e.g. in 200 ; 7a,b or 02 2; 7a,b (Table 1A, deposited) or $T_{i}^{A}$ and $T_{i}^{B}$ values of both $A$ and $B$ components deviate for $i>3$.

Some structures in Table 2(a) exhibit identical Cowley short-range order parameters $\alpha_{i}$, but have different compositions $y / x$. These series of homologous structures have identical unit cells which are filled up successively by $A$ atoms until $T_{i}^{\max }$ is reached (Table 3). Each $A$ and each $B$ atom of these structures must have the same set of numbers $T_{1}, T_{2}$ and $T_{3}$, respectively. The structure with maximum $r^{*}=(y / x)_{\max }$ value, $T_{1}^{*} T_{2}^{*} T_{3}^{*} ; r^{*}$, is filled up with $A$ atoms in steps of $k=r^{*}, \ldots 1,0$ to complete occupation with $A$ atoms at $y / x=0$ (Hauck \& Mika, 1994)

$$
\begin{aligned}
T_{i}(k) & =T_{i}^{\max }-\left(T_{i}^{\max }-T_{i}^{*}\right) k / r^{*}, \\
y / x & =k /\left(r^{*}+1-k\right) .
\end{aligned}
$$

These homologous series of structures also contain structures with $2 k \leq r^{*}$ in Table 3 having $A$ and $B$ atoms interchanged,

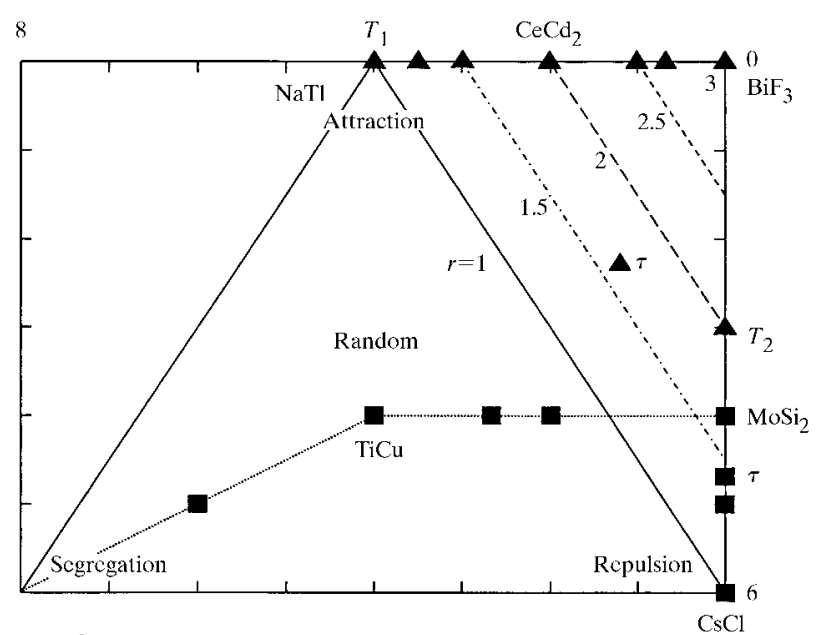

Figure 4

$T_{1}, T_{2}$ structure map of ordered b.c.c. $A_{x} B_{y}$ compounds $T_{1} T_{2} T_{3} ; y / x$ for the [001] (₫) and [111] (ム) layered compounds (Table $2 b$ ). 
similar to $\mathrm{AuCu}_{3}$ and $\mathrm{CuAu}_{3}$ in the f.c.c. lattice (Hauck \& Mika, 1994).

All structures of homologous series are usually at corners or edges of the structure map. In a few cases only the structures with maximum $r^{*}=(y / x)_{\max }$ values are on the border (homologous II series, see \$5). Other series of structures with identical unit cells are on the same border of the structure map with different $\alpha_{i}$ values (quasi-homologous structures).

The existence of homometric and homologous series of structures (with identical $\alpha_{i}$ values), as introduced above, shows that a single set of interaction parameters $V_{i}$ can give rise to different structures. A final remark concerns homometric structures: these were not found in investigations of the Ising model (Ducastelle, 1991; Allen \& Cahn, 1972; Finel \& Ducastelle, 1984; Kanamori \& Kakehashi, 1977).

Most of the observed crystal structures of ordered b.c.c. alloys (Parthé et al., 1993) can be related to three different series of structures (Table $2 b$ ): The combination of 444 ; 1 a and $0612 ; 1$ to give 2.7 $4.76 .7 ; 1$ [Fig. 1A(a), deposited], the combination of $206 ; 2$ and 03 9; 2 to give $0.728 ; 2$ [Fig. $1 \mathrm{~A}(d)$, deposited] and structures which can be considered as $\mathrm{CsCl}$ defect structures. Closely related structures with different composition were included within these series (Table $2 b$ ). For example, the $\mathrm{Ti}_{2} \mathrm{Cu}_{3}$ and $\mathrm{Ti}_{3} \mathrm{Cu}_{4}$ structures can be obtained by a combination of the $\mathrm{MoSi}_{2}$ (0 4 4; 2) and $\gamma$-TiCu (4 4 4; 1) structures [Fig. 2A(a), deposited]. $\mathrm{Au}_{2} \mathrm{Nb}_{3}$ can be considered as a combination of $444 ; 2$ and $\gamma$ TiCu (4 4 4; 1). $\mathrm{Ti}_{3} \mathrm{Pd}_{5}$ and $\mathrm{Os}_{2} \mathrm{Al}_{3}$ are combinations of $\mathrm{MoSi}_{2}(044 ; 2)$

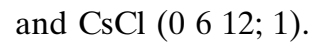

The $039 ; 2$ structure is realised for $\mathrm{SiFe}_{2}(\mathrm{HT})$ and $\mathrm{Ti}$ or $\mathrm{Al}$ atoms in the $(\mathrm{Nb}, \mathrm{Al})(\mathrm{Nb}, \mathrm{Ti}) \mathrm{Ti}_{2} \mathrm{Al}_{2}$ structure [Fig. 2A(b), deposited]. The 20 6; 2 structure occurs for $\mathrm{CeCd}_{2}$ or for $\mathrm{PbLi}_{2}$, which is part of
Table 2

(a) Coordination $T_{1}, T_{2}$ and $T_{3}$ of $A$ atoms and composition $y / x$ in b.c.c..

$A=\mathrm{W}, \mathrm{Pa}, \mathrm{Np}\left(M^{i}=1\right)$ and b.c.c. $A_{x} B_{y}$ with single $T_{i}(A)$ and $T_{i}(B)$ values $\left(M^{i}=2, \S 2\right)($ Fig. $1 \mathrm{~A}$, deposited $)$ [homometric structures $a, b$ are indicated by curly brackets, $T_{i} ; y / x$ values in brackets are not at the border of the structure map (Fig. 4)], coordination of $A$ atoms and composition in square [or hexagonal (*)] planes, space group (SG) and Pearson symbol (PS), No. of reduced unit cell in Table 1A (deposited) and positions of atoms $A_{2}-A_{4}$ in addition to $A_{1}$ in the origin.

\begin{tabular}{|c|c|c|c|c|c|c|c|}
\hline $\begin{array}{l}T_{i}(A) ; y / x \\
\text { b.c.c. }\end{array}$ & $\begin{array}{l}T_{i}(A) ; y / x \\
\text { square }\end{array}$ & SG & PS & No. & $A_{2}$ & $A_{3}$ & $A_{4}$ \\
\hline 86 12; (1) & 44 4; (1) & 229 & cI21 & 1 & & & \\
\hline$(646 ; 1) \dagger$ & $220 ; 1$ & 67 & $o C 8$ & 7 & $1 \overline{1} 1$ & & \\
\hline$(535 ; 1) \dagger$ & $124 ; 1$ & 2 & $a P 8$ & 40 & $\overline{1} 13$ & $\overline{2} 04$ & 002 \\
\hline$(444 ; 1 a) \dagger$ & $444 ;(1)$ & 129 & $t P 4$ & 10 & 111 & & \\
\hline$(444 ; 1 b) \dagger$ & $204 ; 1$ & 131 & $t P 8$ & 45 & 002 & 131 & 111 \\
\hline$(434 ; 1) \dagger$ & $122 ; 1$ & 11 & $m P 8$ & 46 & $1 \overline{1} 3$ & 111 & 002 \\
\hline$(426 ; 1 a)$ & $220 ; 1$ & 11 & $m P 4$ & 8 & $0 \overline{2} 2$ & & \\
\hline (4 $26 ; 1 b)$ & $220 ; 1$ & 66 & $o C 16$ & 52 & 202 & $\overline{1} 11$ & 111 \\
\hline$(425 ; 1)$ & $124 ; 1$ & 2 & $a P 8$ & 39 & $\overline{2} 02$ & $\overline{1} \overline{3} 3$ & $0 \overline{2} 2$ \\
\hline$(424 ; 1 a) \dagger$ & $204 ; 1$ & 65 & $o C 4$ & 2 & & & \\
\hline$(424 ; 1 b) \dagger$ & $204 ; 1$ & 141 & $t I 16$ & 55 & $\overline{1} \overline{1} 1$ & $1 \overline{1} \overline{1}$ & 200 \\
\hline$(418 ; 1) \dagger$ & $044 ; 1$ & 74 & $o I 16$ & 49 & $\overline{1} 13$ & $\overline{1} 11$ & 002 \\
\hline 40 12; 1 & $044 ; 1$ & 227 & $c F 16$ & 13 & 111 & & \\
\hline$(335 ; 1) \dagger$ & $124 ; 1$ & 2 & $a P 8$ & 53 & $0 \overline{2} 0$ & $1 \overline{3} \overline{1}$ & $1 \overline{1} \overline{1}$ \\
\hline$(246 ; 1) \dagger$ & $220 ; 1$ & 74 & $o I 8$ & 12 & $00 \overline{2}$ & & \\
\hline 06 12; 1 & 44 4; (1) & 221 & $c P 2$ & 3 & & & \\
\hline$(424 ; 1.3 a)$ & $222 ; 1.3 \ddagger$ & 2 & $a P 7$ & 31 & $1 \overline{1} 1$ & $2 \overline{2} 0$ & \\
\hline$(424 ; 1.3 b)\}$ & $222 ; 1.3 \ddagger$ & 146 & $h R 7$ & 31 & 002 & $2 \overline{2} 0$ & \\
\hline (2 $33 ; 1.5)$ & $111 ; 1.5$ & 12 & $m C 10$ & 17 & $1 \overline{1} \overline{1}$ & & \\
\hline$(422 ; 2 a) \dagger$ & $\begin{array}{lll}2 & 0 & 2 ; 2 \\
0 & 6 & 0 ; 2\end{array}$ & 69 & $o F 12$ & 4 & & & \\
\hline$(422 ; 2 b) \dagger$ & $060 ; 2 \ddagger$ & 151 & $h P 9$ & 58 & 002 & $1 \overline{1} 1$ & \\
\hline$(222 ; 2) \dagger$ & $060 ; 2 \neq$ & 2 & $a P 9$ & 66 & $0 \overline{2} 2$ & $1 \overline{3} 1$ & \\
\hline $206 ; 2$ & $666 ;(1) \ddagger$ & 164 & $h P 3$ & 5 & & & \\
\hline 04 4; 2 & 44 4; (1) & 139 & $t I 6$ & 6 & & & \\
\hline$(312 ; 2.5)$ & $111 ; 2.5 \ddagger$ & 2 & $a P 7$ & 31 & $2 \overline{2} 0$ & & \\
\hline $200 ; 3$ & $006 ; 3 \ddagger$ & 166 & $h R 4$ & 9 & & & \\
\hline $020 ; 4$ & $000 ; 4$ & 87 & $t I 10$ & 17 & & & \\
\hline $200 ; 6$ & $000 ; 6 \ddagger$ & 148 & $h R 7$ & 31 & & & \\
\hline
\end{tabular}

$\dagger$ On the borders of the $T_{1} T_{2} T_{3} ; y / x$ polyhedron. $\$$ Hexagonal planar.

(b) Structures and $T_{i}(A)$ values of $A_{x} B_{y} C_{z}$ alloys (Fig. 2A, deposited) with sequences of layers $A B(=a), A B B$ $(=b)$ etc. A second space group is given for structures with higher SG than originally reported.

\begin{tabular}{llllll}
\hline$A_{x} B_{y} C_{z}$ & SG & PS & $T_{i}(A)$ & $T_{i}(B)$ & $T_{i}(C / D)$ \\
\hline $\mathrm{W}$ & 229 & $c I 2$ & $8612 ;(1)$ & & \\
LT Pa & 139 & $t I 2$ & $8612 ;(1)$ & & \\
$\beta$-Np & $129 / 90$ & $t P 4$ & $8612 ;(1)$ & & \\
$\alpha$-Np & 62 & $o P 8$ & $8612 ;(1)$ & &
\end{tabular}

Layered (001) structures (Schubert et al., 1960) [Fig. 2A(a) deposited]

\begin{tabular}{|c|c|c|c|c|c|}
\hline $\mathrm{CsCl}$ & $a(A B)$ & 221 & $c P 2$ & $0612 ; 1$ & \\
\hline $\mathrm{MoSi}_{2}$ & $b\left(A B_{2}\right)$ & 139 & $t I 6$ & $044 ; 2$ & \\
\hline $\mathrm{ReSi}_{2}$ & $b$ & 71 & $o I 6$ & $044 ; 2$ & \\
\hline $\mathrm{VAu}_{2}$ & $b$ & $63 / 38$ & $o C 12$ & $044 ; 2$ & \\
\hline $\mathrm{AlAu}_{2}$ & $b$ & 62 & $o P 12$ & $044 ; 2$ & \\
\hline$A B_{3}$ & $c\left(A B_{3}\right)$ & 123 & $t P 4$ & $044 ; 3$ & \\
\hline$\gamma-\mathrm{TiCu}$ & $d\left(A_{2} B_{2}\right)$ & 129 & $t P 4$ & 44 4; 1 & \\
\hline $\mathrm{Au}_{2} \mathrm{Nb}_{3}$ & $e\left(A_{2} B_{3}\right)$ & 139 & $t I 10$ & $444 ; 1.5$ & \\
\hline$A B_{2}$ & $f\left(A_{2} B_{4}\right)$ & 129 & $t P 6$ & $444 ; 2$ & \\
\hline$A B$ & $g\left(A_{4} B_{4}\right)$ & 129 & $t P 8$ & $658 ; 1$ & \\
\hline $\mathrm{Ti}_{3} \mathrm{Cu}_{4}$ & $b d$ & 139 & $t I 14$ & $2.744 ; 1.3$ & \\
\hline $\mathrm{Ti}_{2} \mathrm{Cu}_{3}$ & $b d b$ & 129 & $t P 10$ & 24 4; 1.5 & \\
\hline $\mathrm{Os}_{2} \mathrm{Al}_{3}$ & $a b$ & 139 & $t I 10$ & $058 ; 1.5$ & \\
\hline $\mathrm{Ti}_{3} \mathrm{Pd}_{5}$ & $b a b$ & 123 & $t P 8$ & $04.76 .7 ; 1.7$ & \\
\hline $\operatorname{ReAl}(\operatorname{Re}, \mathrm{Al})_{2}$ & $A C B C$ & 123 & $t P 4$ & $044 ; 3$ & $044 ; 3$ \\
\hline
\end{tabular}

Layered (111) structures (Zalkin \& Ramsey, 1956) [Fig. 2A(b) deposited]

\begin{tabular}{|c|c|c|c|c|}
\hline $\mathrm{CsCl}$ & $h(A B)$ & 221 & $c P 2$ & $0612 ; 1$ \\
\hline $\mathrm{CeCd}_{2}\left(\mathrm{PbLi}_{2}\right)$ & $k\left(A B_{2}\right)$ & 164 & $h P 3$ & $206 ; 2$ \\
\hline $\mathrm{BiF}_{3}, \mathrm{AlFe}_{3}$ & $\begin{array}{l}l\left(A B_{3}\right) \\
m\left(A B_{4}\right)\end{array}$ & $\begin{array}{l}225 \\
166\end{array}$ & $\begin{array}{l}c F 16 \\
h R 15\end{array}$ & $\begin{array}{lll}0 & 0 & 12 ; 3 \\
0 & 0 & 6 \cdot 4\end{array}$ \\
\hline
\end{tabular}


Table 2 (continued)

\begin{tabular}{|c|c|c|c|c|c|c|}
\hline$A_{x} B_{y} C_{z}$ & & SG & PS & $T_{i}(A)$ & $T_{i}(B)$ & $T_{i}(C / D)$ \\
\hline$A B_{5}$ & $n\left(A B_{5}\right)$ & 164 & $h P 6$ & $006 ; 5$ & & \\
\hline $\mathrm{NaTl}$ & $o\left(A_{2} B_{2}\right)$ & 227 & $c F 16$ & $4012 ; 1$ & & \\
\hline $\mathrm{Al}_{2} \mathrm{Li}_{3}$ & $p\left(A_{2} B_{3}\right)$ & 166 & $h R 15$ & $309 ; 1.5$ & & \\
\hline (AlLi) & $q\left(A_{3} B_{3}\right)$ & 164 & $h P 6$ & $428 ; 1$ & & \\
\hline $\mathrm{Pb}_{2} \mathrm{Li}_{7}$ & $\operatorname{lm}$ & $164 / 150$ & $h P 9$ & $009 ; 3.5$ & & \\
\hline$\left(\mathrm{Pb}_{4} \mathrm{Li}_{11}\right)$ & klll & 164 & $h P 15$ & $0.5010 .5 ; 2.75$ & & \\
\hline $\mathrm{Pb}_{3} \mathrm{Li}_{8}$ & $l k l$ & 166 & $h R 33$ & $0.7010 ; 2.7$ & & \\
\hline$\left(\mathrm{Si}_{5} \mathrm{Li}_{13}\right)$ & $l k l k l$ & 164 & $h P 18$ & $0.809 .6 ; 2.6$ & & \\
\hline $\mathrm{Si}_{2} \mathrm{Li}_{5}$ & $k l$ & 166 & $h R 21$ & $109 ; 2.5$ & & \\
\hline $\mathrm{Zn}(\mathrm{Ag}, \mathrm{Zn})_{2}$ & $k$ & 147 & $h P 9$ & $206 ; 2$ & & \\
\hline$A B$ & ho & 156 & $h P 18$ & $2.9210 .7 ; 1$ & & \\
\hline $\mathrm{SiFe}_{2} \mathrm{HT}$ & $h l$ & 164 & $h P 6$ & $039 ; 2$ & & \\
\hline $\mathrm{PtAl}_{2}$ & $h l$ & 164 & $h P 12$ & $039 ; 2$ & & \\
\hline $\mathrm{Ga}_{4} \mathrm{Li}_{5}$ & $o p$ & 164 & $h P 9$ & $3.5010 .5 ; 1.25$ & & \\
\hline$\left(\mathrm{AlLi}_{2}\right)$ & $\operatorname{lp}$ & 164 & $h P 9$ & $2010 ; 2$ & & \\
\hline $\mathrm{Ge}_{2} \mathrm{Cu}_{2} \mathrm{Li}_{5}$ & $A B C_{2} B A C_{3}$ & 164 & $h P 9$ & $009 ; 3.5$ & $106 ; 3.5$ & \\
\hline$(\mathrm{Nb}, \mathrm{Al})(\mathrm{Nb}, \mathrm{Ti}) \mathrm{Ti}_{2} \mathrm{Al}_{2}$, & $A C D B D C$ & 164 & $h P 6$ & $006 ; 5$ & $006 ; 5$ & $039 ; 2$ \\
\hline $\mathrm{Ni}_{2} \square \mathrm{Al}_{3}$ & $A C A C B C$ & 164 & $h P 5$ & $039 ; 2$ & $006 ; 5$ & \\
\hline SnMgLiPd & $A B C D$ & 216 & $c F 16$ & $0012 ; 3$ & $0012 ; 3$ & $0012 ; 3$ \\
\hline $\mathrm{AgSbLi}_{2}$ & $A B C C$ & 216 & $c F 16$ & $0012 ; 3$ & $0012 ; 3$ & $4012 ; 3$ \\
\hline $\mathrm{AlMnCu}_{2}$ & $A C B C$ & 225 & $c F 16$ & $0012 ; 3$ & $0012 ; 3$ & $0612 ; 1$ \\
\hline $\mathrm{VSnRh}_{2}$ & $A C B C$ & 139 & $t I 8$ & $0012 ; 3$ & $0012 ; 3$ & $0612 ; 1$ \\
\hline $\mathrm{USnPd}_{2}$ & $A C B C$ & $69 / 62$ & $o F 16$ & $0012 ; 3$ & $0012 ; 3$ & $0612 ; 1$ \\
\hline \multicolumn{7}{|c|}{$\mathrm{CsCl}$ related structures with composition of $\mathrm{Cs} / \mathrm{Cl}$ layers [Figs. $2 \mathrm{~A}(a)$ and $(b)$ deposited] } \\
\hline $\mathrm{Au}(\mathrm{Zn}, \mathrm{Au})_{3}$ & $A_{2} B_{2} / B_{4}$ & $63 / 26$ & $o C 16$ & $046 ; 3$ & & \\
\hline$(\mathrm{Mo}, \mathrm{U}) \mathrm{U}_{3}$ & $A B / B_{2}$ & 123 & $t P 4$ & $024 ; 3$ & & \\
\hline $\mathrm{Zn}_{3} \mathrm{Ga}_{4} \mathrm{Pd}_{7}$ & $A_{3} B_{4} / C_{7}$ & 146 & $h R 42$ & $024 ; 3.7$ & $036 ; 2.5$ & $0612 ; 1$ \\
\hline $\mathrm{Pu}_{3} \mathrm{Pd}_{4}$ & $A_{6} B / B_{7}$ & 148 & $h R 42$ & $0510 ; 1.3$ & & \\
\hline $\mathrm{CsCl}$ & $A / B$ & 221 & $c P 2$ & $0612 ; 1$ & & \\
\hline UCo & $A / B$ & 199 & $c I 16$ & $0612 ; 1$ & & \\
\hline RT AuCd & $A / B$ & 157 & $h P 18$ & $0612 ; 1$ & & \\
\hline $\mathrm{La}(\mathrm{Ag}, \mathrm{In})$ & $A / B$ & 139 & $t I 16$ & $0612 ; 1$ & & \\
\hline$\delta-\mathrm{TiCu}$ & $A / B$ & 123 & $t P 2$ & $0612 ; 1$ & & \\
\hline RT PuGa & $A / B$ & 107 & $t I 16$ & $0612 ; 1$ & & \\
\hline$\alpha-\operatorname{VIr}$ & $A / B$ & 65 & $o C 8$ & $0612 ; 1$ & & \\
\hline $\mathrm{NaHg}$ & $A / B$ & 63 & $o C 16$ & $0612 ; 1$ & & \\
\hline $\mathrm{Au}(\mathrm{Cu}, \mathrm{Zn})$ & $A / B$ & 55 & $o P 8$ & $0612 ; 1$ & & \\
\hline $\mathrm{Au}(\mathrm{Zn}, \mathrm{Au})$ & $A / B$ & 26 & $o P 16$ & $0612 ; 1$ & & \\
\hline $\mathrm{KHg}$ & $A / B$ & 2 & $a P 8$ & $0612 ; 1$ & & \\
\hline \multicolumn{7}{|c|}{ Other structures [Fig. 2A(a) deposited] } \\
\hline $\mathrm{Pb}_{5} \mathrm{Li}_{22}$ & & $216 / 196$ & $c F 432$ & $004.8 ; 4.4$ & & \\
\hline $\operatorname{In}_{3} \mathrm{Li}_{13}$ & & 227 & $c F 128$ & $004 ; 4.3$ & & \\
\hline $\mathrm{Sb}_{2} \mathrm{Tl}_{7}$ & & 229 & $c I 54$ & $014 ; 3.5$ & & \\
\hline $\mathrm{AuMn}_{3}$ & & 123 & $t P 12$ & $02.674 ; 3$ & & \\
\hline $\mathrm{Sn}_{3} \mathrm{Li}_{7}$ & & 11 & $m P 20$ & $03.34 ; 2.3$ & & \\
\hline $\mathrm{GaLi}_{2}$ & & 63 & $o C 12$ & $208 ; 2$ & & \\
\hline $\mathrm{V}_{4} \mathrm{Zn}_{5}$ & & 139 & $t I 18$ & $434 ; 1.2$ & & \\
\hline
\end{tabular}

(Schubert et al., 1960), $\mathrm{Ti}_{2} \mathrm{Cu}_{3}$ and $\mathrm{Ti}_{3} \mathrm{Cu}_{4}$ (Schubert et al., 1964), $\mathrm{Pb}_{2} \mathrm{Li}_{7}$ (Zalkin \& Ramsey, 1956) and $\mathrm{Pb}_{3} \mathrm{Li}_{8}$ (Zalkin et al., 1956).

The $\mathrm{Zn}_{3} \mathrm{Ga}_{4} \mathrm{Pd}_{7}$ and $\mathrm{Pu}_{3} \mathrm{Pd}_{4}$ structures of Fig. $2 \mathrm{~A}(b)$ (deposited) are closely related to the $\mathrm{CsCl}(A B)$ structure, but with larger unit cells because of the different stoichiometry. Some of the $A=\mathrm{Zn}, \mathrm{Ga}, \mathrm{Pu}, \mathrm{Cs}$ sites are occupied by $B=\mathrm{Pd}, \mathrm{Cl}$. A similar situation occurs for $\mathrm{AlFe}_{3}$, $\mathrm{AlMnCu}_{2}$ (Heusler alloy), $\mathrm{AgSbLi}_{2}$ and $\mathrm{SnMgLiPd}$ [Fig. 2A(a), deposited]. The $\mathrm{Sn}, \mathrm{Mg}, \mathrm{Li}$ and Pd atoms of SnMgLiPd can be combined in five different ways to yield $\mathrm{CsCl} \quad[(\mathrm{Sn}, \mathrm{Mg})(\mathrm{Li}, \mathrm{Pd})]$, $\mathrm{AlMnCu}_{2}\left[\mathrm{SnMg}(\mathrm{Li}, \mathrm{Pd})_{2}\right], \mathrm{AlFe}_{3}$ $\left[\mathrm{Sn}(\mathrm{Mg}, \mathrm{Li}, \mathrm{Pd})_{3}\right], \mathrm{AgSbLi}_{2}$ [LiSn$\left.(\mathrm{Mg}, \mathrm{Pd})_{2}\right]$ or NaTl$[(\mathrm{Sn}, \mathrm{Li})(\mathrm{Mg}, \mathrm{Pd})]$. The combination is similar to the sphalerite-related structures (Hauck \& Mika, 1998a) or the combination of two 004 ; 3 square layers to give 044 ; 1 (Fig. 1) as was outlined in step (ix), $\S 1$.

The sequence $\mathrm{Ni} \mathrm{Al} \mathrm{Ni} \mathrm{Al} \square \mathrm{Al}$ of vacancies $\square=B$ in the $\mathrm{Ni}_{2} \square \mathrm{Al}_{3}$ structure $(A C A C B C)$ (Table $2 b$ ) can alternate in a sequence of Fibonacci numbers, if the composition is varied to $\mathrm{Ni}_{1.85} \square_{1.15} \mathrm{Al}_{3}$ (Chattopadhyay et al., 1987).

The structures of Po $(\S 5)$ and diamond have the same $T_{i}(A)$ values as $\mathrm{CsCl}(\square \mathrm{Po})$ and $\mathrm{NaTl}$ $(\square \mathrm{C})$, respectively, with vacant Cs or $\mathrm{Na}$ positions. The number of vacancies $\square$ is increased to $432-58=374$ in an idealized $\alpha$-Mn ( $001.24 ; 6.45)$ with the

the $\mathrm{Pb}_{3} \mathrm{Li}_{8}$ structure. The $\mathrm{Pb}_{3} \mathrm{Li}_{8}, \mathrm{Al}_{2} \mathrm{Li}_{3}$ and $\mathrm{Si}_{2} \mathrm{Li}_{5}$ structures can be divided in structural units similar to the $206 ; 2-039 ; 2$ series [Fig. 2A(b), deposited]. $\mathrm{CsCl}$ is also a structural unit for combinations in the [111] direction (layers of $\mathrm{Cs}$ and $\mathrm{Cl}$ atoms, which alternate in the [111] direction).

The two families of structures with sequences of $A$ or $B$ atom layers in the [001] or [111] direction can be described by sequences of structural units $a$ ( $\widehat{=}$ layer sequence $A B), b$ ( layer sequence $A B B$ ) etc. (Table $2 b$ ), similar e.g. to the Ruddlesden-Popper and Aurivillius phases with sequences of $v$ or $v^{\prime}\left(\mathrm{CaTiO}_{3}\right)$ and $w^{\prime}(\mathrm{SrO})$ or $W^{\prime}\left(\mathrm{WBi}_{2} \mathrm{O}_{6}\right)$ structural units, respectively (Hauck \& Mika, 1997). The present families of structures are also named by the pioneers who investigated the crystal structures of the first example of the series: $\mathrm{Au}_{2} \mathrm{Nb}_{3}$ $x, y, z$ parameters of the $58 \mathrm{Mn}$ atoms $1 / 3(w=0.317$, $u=0.356), 1 / 4\left(v^{\prime}=0.278\right), 1 / 12\left(u^{\prime}=0.089\right)$ and $0(v=0.042)$ rather than the observed values in brackets (Wyckoff, 1982).

The metal atoms of the idealized superconducting oxides (Hauck \& Mika, 1997, 1998b) lie on a b.c.c. lattice with structures similar to the Schubert family. The metal lattices of $\mathrm{CuLa}_{2} \mathrm{O}_{4}$ and $\mathrm{LaCu}_{2} \mathrm{La}_{2} \mathrm{O}_{7}$ correspond to $\mathrm{MoSi}_{2}$ and $\mathrm{Os}_{2} \mathrm{Al}_{3}$ $\left(\mathrm{AlOs}_{2} \mathrm{Al}_{2}\right.$; Table $\left.2 b\right)$. The formulae $\mathrm{Cu}^{\prime} \mathrm{La}_{2} \mathrm{O}_{4}, \mathrm{La}^{\prime} \mathrm{Cu}_{2} \mathrm{La}_{2} \mathrm{O}_{7}$ and $\mathrm{Cu}^{\prime} \mathrm{Ba}_{2} \mathrm{Cu}_{2} \mathrm{Y}^{\prime} \mathrm{O}_{7}$ (instead of $\mathrm{La}_{2} \mathrm{CuO}_{4}, \mathrm{La}_{3} \mathrm{Cu}_{2} \mathrm{O}_{7}$ and $\mathrm{YBa}_{2} \mathrm{Cu}_{3} \mathrm{O}_{7}$ ) show the sequence of metal atoms $\mathrm{Cu}^{\prime} \mathrm{LaLa}$, $\mathrm{La}^{\prime} \mathrm{CuLaLaCu}$ and $\mathrm{Cu}^{\prime} \mathrm{BaCuY} \mathrm{Y}^{\prime} \mathrm{CuBa}$ with a single $\mathrm{Cu}^{\prime}, \mathrm{La}^{\prime}$ and $\mathrm{Y}^{\prime}$ at mirror planes and two other atoms left and right of the mirror plane. 


\section{Face-centered cubic alloys $A_{x} B_{y}$}

The face-centered cubic structure is obtained if spheres with diameter $d$ are ordered with the cubic close-packed structure. The distance between two identical square layers of the facecentered $\mathrm{Cu}$ structure $a_{0}=2^{1 / 2} d$ can be increased up to $1.66 d$ in In, $\mathrm{Ga}, \mathrm{La}$ or $\mathrm{Ce}$, or decreased to $1.33 d$ in $\mathrm{Pu}$ or $1.0 d$ in W (Wyckoff, 1982; Ho \& Douglas, 1968; Pearson, 1972; Villars \& Calvert, 1986; Hyde \& Andersson, 1989; Parthé et al., 1993). The undistorted structures are compared in the present paper using the self-coordination numbers $T_{i}$ of b.c.c. and f.c.c. alloys and their different locations on structure maps.

The 28 structures of ordered f.c.c. $A_{x} B_{y}$ with single $T_{1} T_{2} T_{3}$; $y / x$ values $\left(M^{i}=2, \S 2\right)$ are listed in Table $4(a) .15$ of these structures are at the corners of the structure map (Fig. 5). Only seven structures were obtained by the Ising model (Kanamori \& Kakehashi, 1977). The 126 24; (1), 60 12; 1a,b, 44 16; 1 and $468 ; 1$ structures are the limiting structures at $y / x=1$ (Fig. 5). 60 12; 1a,b, 53 12; 1a,b and 42 12; 1.3a,b are homometric structures - structures with identical $T_{i}$ values, but different symmetry as was outlined in $\S 3$. Other structures such as 22 $12 ; 2 \mathrm{a}, \mathrm{b}, \mathrm{c}$ are 'quasi-homometric' with some deviations of higher $T_{i}$ values. The lattice energies of the undistorted lattices as given by the Madelung factors are slightly different (Hauck et al., 1988b,d).

The 06 0; $3 \mathrm{AuCu}_{3}, 468 ; 1 \mathrm{CuAu}, 2212 ; 2 \mathrm{a} \mathrm{MoPt}_{2}$ and 028 ; $4 \mathrm{MoNi}_{4}$ structures are within homologous series of structures with identical $\alpha_{i}$ values (Table 5), as was outlined for b.c.c. alloys in $\S 3$.

Three different series of experimental structures are shown in Figs. $3 \mathrm{~A}(a)-(c)$ (deposited). The compilation (Table $4 b$ ) also includes some theoretical structures and some $\mathrm{NaCl}$ (Hauck et al., 1988c) or ZnS (Hauck \& Mika, 1998a) derivative structures, which are shown in Figs. $3 \mathrm{~A}(a)-(d)$ (deposited), if the corresponding structures of alloys are not known. The Na and $\mathrm{Cl}$ atoms of the $\mathrm{NaCl}$ structure form two f.c.c. lattices with a translation $a_{0} / 2, a_{0} / 2, a_{0} / 2$ of the lattice constant $a_{0}$. The f.c.c. lattices of $\mathrm{ZnS}$ (sphalerite) are translated by $a_{0} / 4, a_{0} / 4, a_{0} / 4$. The ordering of metal atoms at $\mathrm{Na}$ or $\mathrm{Zn}$ positions or nonmetal atoms at $\mathrm{Cl}$ or $\mathrm{S}$ positions can be characterized by the s$\mathrm{CN}$ values $T_{i}$ similar to alloys. In $\alpha-\mathrm{NaFeO}_{2}$, e.g. the $\mathrm{Na}$ and $\mathrm{Fe}$ atoms occupy the same positions as the $\mathrm{Cu}$ and $\mathrm{Pt}$ atoms in $\mathrm{CuPt}$,a (Table $4 b$ ). The corresponding $\mathrm{ZnS}$ derivative structure is $\operatorname{In}(\mathrm{Ga}, \mathrm{Al}) \mathrm{P}_{2}$ with a disordered distribution of $\mathrm{Ga}$ and $\mathrm{Al}$ atoms at the $\mathrm{Pt}$ positions of the $\mathrm{CuPt}$ structure. $\mathrm{In} \mathrm{Cd} \square \mathrm{Cl}_{2}$ and $\mathrm{Gd}_{2} \square \mathrm{C}$ the $\mathrm{Cd}$ atoms and vacancies $\square$ or the $\mathrm{C}$ atoms and vacancies form the CuPt structure. In $\square \mathrm{Nb}_{3} \square \mathrm{O}_{3}$ the metal $\square \mathrm{Nb}_{3}$ and non-metal sublattices $\square \mathrm{O}_{3}$ are both ordered as in the $\mathrm{AuCu}_{3}$ structure. The space group number and Pearson symbol listed in Table $4(b)$ correspond to the compounds $A_{x} B_{y} C_{z}$.

The $T_{1}$ and $T_{2}$ values in the $T_{1} T_{2} T_{3} ; y / x$ notation of NaClrelated compounds describe the connection of octahedra by edges and corners, respectively. For example, the $107 ; 4 \mathrm{UCl}_{5}$ structure contains $\mathrm{UCl}_{6}$ octahedra connected by one edge to form $\left(\mathrm{UCl}_{5}\right)_{2}$, while the $\mathrm{UF}_{6}$ octahedra of $028 ; 4 \mathrm{UF}_{5}$ are connected by two corners in a one-dimensional row. $\mathrm{The}^{\mathrm{CTi}}{ }_{6}$

\section{Table 3}

$\mathrm{s}-\mathrm{CN}$ values of some homologous series of b.c.c. derivative structures (Fig. $1 \mathrm{~A}$, deposited) with different $r$ and $k$ values (see text).

\begin{tabular}{lll}
\hline$r^{*}$ & $k$ & $T_{i}(A)$ \\
\hline 6 & 6 & $200 ; 6$ \\
6 & 5 & $312 ; 2.5$ \\
6 & 4 & $424 ; 1.33 \mathrm{a}, \mathrm{b}$ \\
6 & 3 & $536 ; 0.75 \mathrm{a}, \mathrm{b}$ \\
6 & 2 & $648 ; 0.4$ \\
6 & 1 & $7510 ; 0.17$ \\
6 & 0 & $8612 ;(0)$ \\
& & \\
4 & 4 & $230 ; 4$ \\
4 & 3 & $446 ; 0.67$ \\
4 & 2 & $659 ; 0.25$ \\
4 & 1 & $8612 ;(0)$ \\
4 & 0 & $200 ; 3$ \\
& & $424 ; 1 \mathrm{a}, \mathrm{b}$ \\
3 & 3 & $648 ; 0.33$ \\
3 & 2 & $8612 ;(0)$ \\
3 & 1 & \\
3 & 0 &
\end{tabular}

octahedra of 60 12; $1 \mathrm{~b} \mathrm{Ti}{ }_{2} \mathrm{C}$ are linked by six edges, the $\mathrm{NTi}_{6}$ octahedra of $4416 ; 1 \mathrm{Ti}_{2} \mathrm{~N}$ are linked by four edges and four corners. The vacancies $\square$ of $008 ; 5 \mathrm{~V}_{6} \mathrm{C}_{5} \square$ or the Re atoms of 0 0 8; $5 \mathrm{Li}_{5} \mathrm{ReO}_{6}$ form isolated octahedra. Usually the metal atoms with high valency such as $\mathrm{U}^{5+}$ or $\mathrm{Re}^{7+}$ are as far apart as possible with low $T_{1}$ and $T_{2}$ values because of repulsive interactions.

The number $T_{1}$ of nearest neighbors of $\mathrm{ZnS}$ derivative structures corresponds to the number of $\mathrm{ZnS}_{4}$ tetrahedra shared by corners. In e.g. $(\mathrm{Ni}, \mathrm{Cu})_{5} \mathrm{Si}_{2} \mathrm{~S}_{7}$ with an ordering of $\mathrm{Si}$ atoms as in the $\mathrm{Mn}_{2} \mathrm{Au}_{5}$ alloy $(1310 ; 2.5)$, each $\mathrm{SiS}_{4}$ tetrahedron is linked to another $\mathrm{SiS}_{4}$ tetrahedron in $\mathrm{Si}_{2} \mathrm{~S}_{7}$ groups.

Pauling's electrovalence rule is satisfied for all $\mathrm{NaCl}$ derivative structures with composition $r=y / x=1,2$ and 5 along the upper right-hand border of the structure map with $T_{2}=$ $-2 T_{1}+6(3-r)$ for $1 \leq r \leq 2$ and $T_{2}=-2 T_{1}+2(5-r)$ for $2 \leq r \leq 5$, and for all $\mathrm{ZnS}$ derivative structures with composition $r=y / x=1$ and 3 along the right-hand border $\left(T_{1}=6-2 r\right.$; Hauck \& Mika, 1994, 1998a). The Ti atoms of $\mathrm{Ti}_{2} \mathrm{C} \square(6012 ; 1$ a structure $)$ and $\mathrm{Ti}_{2} \mathrm{~N} \square(4416 ; 1$ structure $)$ at the two ends of the $T_{2}=-2 T_{1}+12$ line are surrounded by three $\mathrm{C}$ atoms in a facial configuration in $\mathrm{Ti}_{2} \mathrm{C}$ and three $\mathrm{N}$ atoms in a meridional configuration in $\mathrm{Ti}_{2} \mathrm{~N}$, because of the different interaction energies between these atoms.

The carbides $\mathrm{Ti}_{2} \mathrm{C}, \mathrm{Gd}_{2} \mathrm{C}, \mathrm{Ti}_{8} \mathrm{C}_{5}, \mathrm{~V}_{6} \mathrm{C}_{5}$ and $\mathrm{V}_{8} \mathrm{C}_{7}$ are located at low $T_{2}$ values of the structure map, indicating covalent-type bonding, while the nitrides $\mathrm{Ti}_{2} \mathrm{~N}, \mathrm{Nb}_{4} \mathrm{~N}_{3}$ and the hydrides $\mathrm{Pd}_{2} \mathrm{H}, \mathrm{Pd}_{5} \mathrm{D}_{4}$ are located at increased $T_{2}$ values, indicating Coulomb-type interactions (Table $4 b$; Hauck \& Mika, 1994).

The $\mathrm{N}$ atoms of $\mathrm{Ti}_{2} \mathrm{~N}$ are further apart than the $\mathrm{C}$ atoms of $\mathrm{Ti}_{2} \mathrm{C}$ and are stabilized by Coulomb interactions with a Madelung factor increased by $1.9 \%$. The $\mathrm{Ti}_{2} \mathrm{C}$ structure is stabilized by covalent forces with a slight reduction in the length of all $\mathrm{Ti}-\mathrm{C}$ bonds (Hauck \& Mika, 1994). A similar situation exists for a cis configuration of the $\mathrm{Sn}$ atoms in 
$\mathrm{Li}_{2} \mathrm{SnO}_{3}(3010 ; 2 \mathrm{~b})$ or mixed cis and trans configuration of $\mathrm{Zr}$ atoms in $\mathrm{Li}_{2} \mathrm{ZrO}_{3}(2212 ; 2 \mathrm{a})$. (The $\mathrm{O}$ atoms occupy all $\mathrm{Cl}$ positions of the $\mathrm{NaCl}$ structure.) A structure with all $\mathrm{Zr}$ atoms in trans configurations is not possible in $\mathrm{NaCl}$ derivative structures. At $y / x=5$, as e.g. in $\mathrm{Li}_{5} \mathrm{ReO}_{6}$ or $\mathrm{V}_{6} \mathrm{C}_{5} \square$, isolated $\mathrm{ReO}_{6}$ or $\square \mathrm{V}_{6}$ octahedra are formed with one Re atom (or $\square$ ) next to each $\mathrm{O}$ (or $\mathrm{V}$ ) atom.

The limiting structures $060 ; 3,048 ; 3,468 ; 1$ and 44 16; 1 can be split into structural units $u, v, x$ and $y$, which can be combined like the parts of a puzzle to obtain the crystal structures found at the right-hand border [Fig. 3A(c), deposited]. The $u^{\prime}, v^{\prime}, x^{\prime}$ and $y^{\prime}$ units are obtained from the $u, v, x$ and $y$ structural units by the translation $a_{0} / 2, a_{0} / 2,0$.

The structures with a single environment of $A$ atoms can be characterized by square or hexagonal layers with small unit cells, as shown in Table 4(a), and one or two structural units such as $x(\mathrm{CuAu})$ or $x y^{\prime} x^{\prime} y(\mathrm{UPb})$ [Fig. 3A(c), deposited]. The $x^{\prime} y$ structural units can be obtained by a shearing of the $x y^{\prime}$ units with the translation $a_{0} / 2, a_{0} / 2,0$. Structures containing several related structural units such as $y x_{9}$ and $y^{\prime} x_{9}^{\prime}$ in CuAu II with the sequence $y x_{9} y^{\prime} x_{9}^{\prime}$ [Fig. 3A(c), deposited] are considered as shear structures with antiphase boundaries between $y x_{9}$ and $y^{\prime} x_{9}^{\prime}$ (Schubert, 1964; Sato \& Toth, 1965; Hyde \& Andersson, 1989). Other structures of Fig. 3A(c) (deposited) such as $\mathrm{ZrGa}_{2}$ exhibit a symmetrical sequence of structural units (vyuuyv).

The observed structures (Table $4 b$ ) as e.g. the $\mathrm{CuAu}$ II or $\mathrm{ZrAl}_{3}$ structure at the right-hand boundary of the structure map (Fig. 5) consist of $u, v, x, y$ structural units, which are connected by 044 ; 1 square planes (Fig. 1). The other layers of

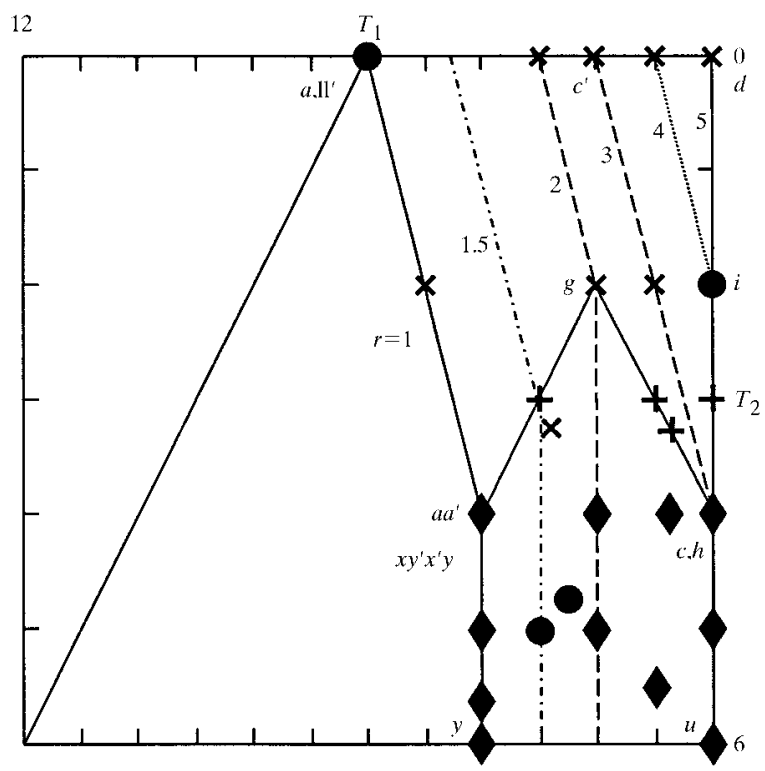

Figure 5

Structure map of ordered f.c.c. $A_{x} B_{y}$ alloys with s-CN values of $A$ atoms as parameters and structural units $a-y$. The boundary of the structure map is outlined for $r=y / x$ by differently dashed lines. The $T_{1}$ and $T_{2}$ values of the Johansson \& Linde and Brauer $(\bullet)$, Ketelaar $(x)$ and Forsyth \& Gran families (+) and the [001] (ロ) or [111] (ム) layered structures are in different areas of the structure map. the $\mathrm{CuAu}-\mathrm{UPb}$ and $\mathrm{AuCu}_{3}-\mathrm{TiAl}_{3}$ parent structures do not fit together. The structural units of many structures on the righthand side of the structure map (Fig. 5) are connected by 204 ; 1 or 044 ; 1 square planes (Table $4 a$ ). The (theoretical) structures on the left-hand side of the structure map are connected by 66 6; (1) hexagonal planes (Hauck \& Mika, 1994). $\mathrm{Al}_{2} \square_{2} \mathrm{C}_{3}$ (ac') (Ketelaar, 1935; Ketelaar et al., 1947), $\mathrm{Mo}_{3} \mathrm{Al}_{8}\left(g h_{2}\right)$ (Forsyth \& Gran, 1962), CuAu II $\left(y x_{9} y^{\prime} x_{9}^{\prime}\right)$ (Johansson \& Linde, 1936) and $\mathrm{ZrAl}_{3}\left(v_{4} v_{4}^{\prime}\right)$ (Brauer, 1939) are the first structures of the three structure families (Table $4 b$ ).

The $A B_{3}$ structures such as $\mathrm{TiAl}_{3}\left(u_{2} u_{2}^{\prime}\right)$ or $\mathrm{ZrAl}_{3}\left(v_{4} v_{4}^{\prime}\right)$ (Brauer, 1939) are obtained from $u$ and $v$ units and the $A B$ structures such as $y x_{9} y^{\prime} x_{9}^{\prime}$ (CuAu II) (Johansson \& Linde, 1936) from a combination of the $x$ and $y$ structural units. The structures with intermediate composition such as $A B_{2}$ are obtained by combination of $u, v, x$ and $y$ units [Table $4 b$, Fig. $3 \mathrm{~A}(c)$, deposited]. The NaCl-related structures at the righthand border of the structure map contain vacancies in the structural units to approach Pauling's electrovalence rule such as $u_{2}$ for $\square \mathrm{Nb}_{3} \square \mathrm{O}_{3}(\mathrm{NbO}), v^{\prime} x u_{2} x v^{\prime}$ for $\mathrm{V}_{2} \square_{4} \mathrm{O}_{5} \square\left(\mathrm{V}_{2} \mathrm{O}_{5}\right)$, $u x v^{\prime} x^{\prime} u^{\prime}$ for $\mathrm{Mo}_{2} \square \mathrm{O}_{3}\left(\mathrm{MoO}_{3}\right), u_{2} x v_{4}^{\prime} x u_{2}$ for $\mathrm{Nb}_{3} \square_{7} \mathrm{FO}_{7} \square_{2}$ $\left(\mathrm{Nb}_{3} \mathrm{O}_{7} \mathrm{~F}\right), x v_{2}^{\prime} x u_{2}$ for $\mathrm{Nb}_{2} \square_{4} \mathrm{O}_{5} \square\left(R-\mathrm{Nb}_{2} \mathrm{O}_{5}\right)$ or the twodimensional shear structures of e.g. ( $\mathrm{Au}, \mathrm{Zn}) \mathrm{Cu}_{3}, \mathrm{ZnAu}_{3}$ (Schubert, 1964; Sato \& Toth, 1965), $\left(\mathrm{W}_{0.2} \mathrm{~V}_{0.8}\right)_{9} \square_{16} \mathrm{O}_{21} \square_{4}$ $\left[\left(\mathrm{W}_{0.2} \mathrm{~V}_{0.8}\right)_{3} \mathrm{O}_{7}\right]$ or $\quad \mathrm{Nb}_{16} \square_{33} \mathrm{O}_{40} \square_{9} \quad\left(M-\mathrm{Nb}_{2} \mathrm{O}_{5} ;\right.$ Hyde \& Andersson, 1989). The two-dimensional shear structures, however, are not at the border of the structure map and contain different structural elements [hatched areas in Fig. $3 \mathrm{~A}(d)$, deposited]. Non-periodic antiphase boundaries in two dimensions were observed in $\mathrm{ZnAu}_{3}$ (Teuho et al., 1987).

Some of the remaining observed structures (Table $4 b$ ) can be classified in a similar way to the three structure families of ordered b.c.c. structures (Table $2 b$ ). The square layers of $A$

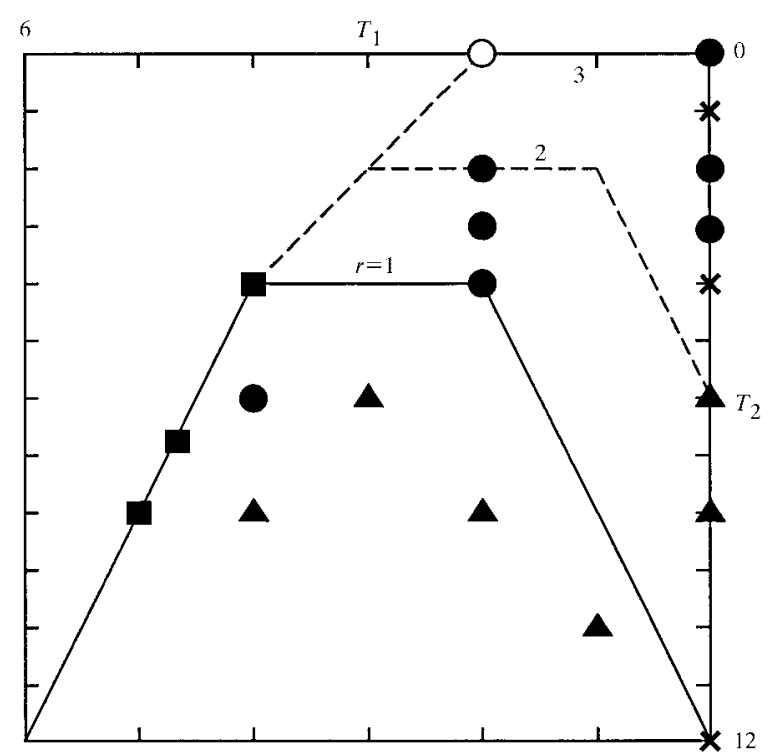

Figure 6

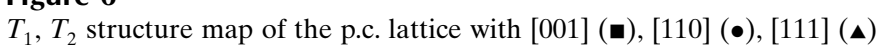
layered, $\mathrm{ZnS}$ related $(\times)$ and other $(\circ)$ compounds in different areas. 
atoms perpendicular to the drawing plane are separated by layers of $B$ atoms in TiCd and $\mathrm{CuZr}_{2}$ similar to $\gamma-\mathrm{TiCu}$ and $\mathrm{MoSi}_{2}$ (Table 2b). These compounds with $T_{i}$ values 848 ; 1 (TiCd) and $440 ; 2\left(\mathrm{CuZr}_{2}\right)$, which are not at the border of the f.c.c. structure map ( $\square$ ) (Fig. 5), should be considered as distorted $\gamma$ - $\mathrm{TiCu}$ or $\mathrm{MoSi}_{2}$ with the same space groups and Pearson symbols. Most of the observed structures are at boundary lines for the given composition. The only exceptions in Table $4(b)$ are $\square_{4} \mathrm{Co}_{5} \mathrm{Ge}_{7}$ and $\mathrm{V}_{4} \mathrm{Zn}_{5}$, which should be reinvestigated after extended annealing to avoid a partial disorder which is inherent in all structures inside the structure map.

\section{Primitive cubic lattice}

The crystal structure of $\alpha$-Po has a primitive-cubic (p.c.) structure (Galasso, 1970; Donohue, 1974). More important are the $\mathrm{CaF}_{2}$ derivative structures (Fig. 3) (Müller, 1991; Juza et al., 1959). The $\mathrm{Ca}$ and $\mathrm{F}$ atoms form f.c.c. and p.c. structures, respectively, but only the F lattice is considered here. Some compounds with $\mathrm{CaF}_{2}$ structure such as $\mathrm{CeO}_{2}, \mathrm{PrO}_{2}$ or $\mathrm{TbO}_{2}$ can form oxygen-deficient structures, e.g. $\operatorname{Pr}_{n} \mathrm{O}_{2 n-2}$, where $n=7,9,10,11$, 12 , and some of the oxygen positions are vacant (Schweda et al., 1991; Zhang et al., 1993, 1995a,b, 1996). These compounds and the anions of $\mathrm{PbO}, \mathrm{PtS}$ and $\mathrm{Cu}_{2} \mathrm{O}$ can be described as p.c. compounds $A_{x} B_{y}$ with $A=$ vacancy $(\square)$ and $B=\mathrm{O}$ or $\mathrm{S}$ and metal atoms $\mathrm{Pb}$, $\mathrm{Pt}, \mathrm{Cu}$ at $\mathrm{Ca}$ positions of $\mathrm{CaF}_{2}$. The other compounds shown in Fig. 4A (deposited) are derived from the antifluorite structure of $\mathrm{Li}_{2} \mathrm{O}$ with an ordered distribution of metal atoms such as $\beta-\mathrm{Li}_{5} \mathrm{Al}_{\square_{2}} \mathrm{O}_{4} \quad$ (Stewner \&
Table 4

(a) Cubic close-packed alloys $A_{x} B_{y}$ with single $T_{i}(A)$ and $T_{i}(B)$ values characterized by the s-CN values $T_{i}$ of $A$ atoms in a c.c.p. structure and in square planes (only occupied planes perpendicular to the direction with the highest symmetry are included), space group (SG), Pearson symbol (PS), No. of reduced cells (Table 2A, deposited) and positions of atoms $A_{2}-A_{4}$.

\begin{tabular}{|c|c|c|c|c|c|c|c|}
\hline $\begin{array}{l}T_{i}(A) ; y / x \\
\text { c.c.p. }\end{array}$ & $\begin{array}{l}T_{i}(A) ; y / x \\
\text { square }\end{array}$ & SG & PS & No. & $A_{2}$ & $A_{3}$ & $A_{4}$ \\
\hline 126 24; (1) & 44 4; (1) & 225 & $c F 4$ & 1 & & & \\
\hline $9312 ; 1$ & $666 ;(1) \dagger$ & 166 & $h R 4$ & 7 & 101 & & \\
\hline$(848 ; 1) \ddagger$ & $444 ;(1)$ & 129 & $t P 4$ & 8 & 011 & & \\
\hline (7 $210 ; 1) \ddagger$ & $322 ; 1$ & 11 & $m P 8$ & 43 & 011 & 101 & $1 \overline{1} 2$ \\
\hline (6 2 12; 1a) & $204 ; 1$ & 59 & $o P 4$ & 9 & 011 & & \\
\hline$(6212 ; 1 b)$ & $204 ; 1$ & 131 & $t P 8$ & 47 & $0 \overline{1} 1$ & 101 & 112 \\
\hline$(6112 ; 1)$ & $204 ; 1$ & 11 & $m P 8$ & 41 & 011 & 103 & 002 \\
\hline $6012 ; 1 \mathrm{a}$ & $204 ; 1$ & 166 & $h R 2$ & 2 & & & \\
\hline $6012 ; 1 b$ & $204 ; 1$ & 227 & $c F 32$ & 53 & 110 & 011 & 101 \\
\hline$(5410 ; 1)$ & $122 ; 1$ & 11 & $m P 8$ & 48 & 121 & 101 & 011 \\
\hline$(5312 ; 1 a)$ & $322 ; 1$ & 12 & $m C 8$ & 10 & 002 & & \\
\hline (5 $312 ; 1 b)$ & $222 ; 1$ & 15 & $m C 16$ & 52 & 200 & $3 \overline{1} 0$ & $10 \overline{1}$ \\
\hline $5214 ; 1$ & $122 ; 1$ & 15 & $m C 16$ & 51 & $\overline{1} \overline{1} 2$ & $\overline{1} 01$ & $0 \overline{1} 1$ \\
\hline $468 ; 1$ & 44 4; (1) & 123 & $t P 2$ & 3 & & & \\
\hline $4512 ; 1 \mathrm{a}$ & $044 ; 1$ & 74 & $o I 16$ & 45 & $0 \overline{1} 3$ & $0 \overline{1} 1$ & 002 \\
\hline $4416 ; 1$ & $044 ; 1$ & 141 & $t I 8$ & 13 & $0 \overline{1} 1$ & & \\
\hline $4212 ; 1.3 a$ & $222 ; 1.3 \dagger$ & 2 & $a P 7$ & 34 & $1 \overline{1} 0$ & $0 \overline{1} 1$ & \\
\hline $4212 ; 1.3 b$ & $222 ; 1.3 \dagger$ & 146 & $h R 7$ & 34 & $1 \overline{2} 1$ & $1 \overline{1} 0$ & \\
\hline $3312 ; 1.5$ & $111 ; 1.5$ & 12 & $m C 10$ & 18 & 101 & & \\
\hline $606 ; 2$ & $666 ;(1) \dagger$ & 164 & $h P 3$ & 4 & & & \\
\hline$(440 ; 2) \neq$ & 44 4; (1) & 139 & $t I 6$ & 5 & & & \\
\hline $2212 ; 2 \mathrm{a}$ & $202 ; 2$ & 71 & $o I 6$ & 6 & & & \\
\hline $2212 ; 2 b$ & $060 ; 2 \dagger$ & 151 & $h P 9$ & 62 & $1 \overline{1} 0$ & $1 \overline{2} \overline{1}$ & \\
\hline $2212 ; 2 \mathrm{c}$ & $060 ; 2 \dagger$ & 2 & $a P 6$ & 63 & $3 \overline{1} 0$ & $2 \overline{1} 1$ & \\
\hline $219 ; 2.5$ & $111 ; 2.5 \dagger$ & 2 & $a P 7$ & 34 & $0 \overline{1} 1$ & & \\
\hline $060 ; 3$ & $044 ; 1$ & 221 & $c P 4$ & 12 & & & \\
\hline $028 ; 4 a$ & $0004 ; 4$ & 87 & $t I 10$ & 18 & & & \\
\hline $006 ; 6$ & $0006 ; 6+$ & 166 & $h R 7$ & 34 & & & \\
\hline
\end{tabular}

$\dagger$ Hexagonal planar. $\ddagger$ On the borders of the $T_{2} T_{2} T_{3} ; y / x$ polyhedron.

(b) Structures and $T_{i}(A)$ values of $A_{x} B_{y} C_{z}$ alloys, and corresponding $\mathrm{NaCl}$ and $\mathrm{ZnS}$ derivative structures within different series of structural units and other structures [Figs. $3 \mathrm{~A}(a)-(d)$, deposited, see text].

\begin{tabular}{llllll}
\hline$A_{x} B_{y} C_{z}$ & SG & PS & $T_{i}(A / B / C)$ & NaCl derivative & ZnS derivative \\
\hline $\mathrm{Cu}$ & 225 & $c F 4$ & $12624 ;(1)$ & $\mathrm{NaCl}$ & $\mathrm{ZnS}$ \\
$\alpha-\mathrm{Hg}$ & 166 & $h R 1$ & $12624 ;(1)$ & $\mathrm{NiO}$ & \\
$\mathrm{Al}, \mathrm{Zn}$ metast. & 166 & $h R 1$ & $12624 ;(1)$ & & \\
Pr HP & 152 & $h P 6$ & $12624 ;(1)$ & & \\
In & 139 & $t I 2$ & $12624 ;(1)$ & $\mathrm{CoO}$ & \\
$\gamma$-Mn & 139 & $t I 2$ & $12624 ;(1)$ & & \\
$\alpha^{\prime \prime}-\mathrm{Ce} \mathrm{I}$ & 12 & $m C 2$ & $12624 ;(1)$ & & \\
$\alpha^{\prime \prime}-\mathrm{Ce} \mathrm{II}$ & 12 & $m C 4$ & $12624 ;(1)$ & & \\
$\mathrm{Cf} \mathrm{HP}$ & 2 & $a P 4$ & $12624 ;(1)$ & &
\end{tabular}

[110] structural units $a-d, k, l$ of Ketelaar (1935), Ketelaar et al. (1947) family [Fig. 3A(a), deposited]

\begin{tabular}{|c|c|c|c|c|c|c|}
\hline $\mathrm{CuPt}, \mathrm{a}$ & $a$ & 166 & $h R 2$ & $6012 ; 1 \mathrm{a}$ & $\begin{array}{l}\alpha-\mathrm{NaFeO}_{2} \\
\mathrm{Gd}_{2} \mathrm{C}, \mathrm{CdCl}_{2}\end{array}$ & $\mathrm{In}(\mathrm{Ga}, \mathrm{Al}) \mathrm{P}_{2}$ \\
\hline $\mathrm{CuPt}, \mathrm{b}$ & $l l^{\prime}$ & 227 & $c F 32$ & $6012 ; 1 b$ & $\begin{array}{l}\mathrm{LiTbS}_{2} \\
\mathrm{Ti}_{2} \mathrm{C}, \mathrm{ZrS}_{2}\end{array}$ & \\
\hline$A B$ & $a_{2} a_{2}^{\prime}$ & 66 & $o C 16$ & $5214 ; 1 a$ & $\mathrm{NaDyO}_{2}$ & \\
\hline$A B$ & $a_{3} a^{\prime}$ & 15 & $m C 16$ & $5214 ; 1 b$ & & \\
\hline$A B$ & $b b^{\prime}$ & 67 & $o C 16$ & $5314 ; 1$ & & \\
\hline $\mathrm{UPb}$ & $a a^{\prime}$ & 141 & $t I 8$ & $4416 ; 1$ & $\mathrm{Pd}_{2} \mathrm{D}, \mathrm{Ti}_{2} \mathrm{~N}$ & $\mathrm{CuFeS}_{2}$ \\
\hline$A B$ & $b$ & 131 & $t P 8$ & $4512 ; 1 b$ & & \\
\hline$(\mathrm{Zn}, \mathrm{Ga})_{3} \mathrm{Au}_{5}$ & $b c b^{\prime} c$ & 72 & $o I 32$ & $2.73 .310 .7 ; 1.7$ & & \\
\hline$A_{3} B_{5}$ & $k k^{\prime}$ & 166 & $h R 8$ & $408 ; 1.7$ & $\mathrm{Ti}_{8} \mathrm{C}_{5}$ & \\
\hline$A B_{2}$ & $a c^{\prime}$ & 12 & $m C 12$ & $3010 ; 2 b$ & $\mathrm{AlCl}_{3}, \mathrm{Li}_{2} \mathrm{SnO}_{3}$ & \\
\hline$A B_{2}$ & $a c^{\prime} a^{\prime} c^{\prime}$ & 70 & $o F 48$ & $3010 ; 2 \mathrm{c}$ & $\mathrm{Sc}_{2} \mathrm{~S}_{3}, \mathrm{CrCl}_{3}$ & \\
\hline$A B_{2}$ & $c a^{\prime}$ & 15 & $m C 12$ & $2212 ; 2 \mathrm{~d}$ & $\mathrm{Li}_{2} \mathrm{ZrO}_{3}, \mathrm{III}$ & \\
\hline$A B_{2}$ & $a c a^{\prime} c$ & 70 & $o F 48$ & $2212 ; 2 \mathrm{f}$ & & \\
\hline $\mathrm{CuPt}_{3}$ & $c^{\prime}$ & 65 & $o C 8$ & $204 ; 3$ & $\mathrm{OsCl}_{4}, \mathrm{Tm}_{3} \mathrm{Se}_{4}$ & \\
\hline$A B_{3}$ & $a d^{\prime}$ & 15 & $m C 16$ & $208 ; 3 a$ & & \\
\hline$A B_{3}$ & adad $^{\prime}$ & 15 & $m C 32$ & $208 ; 3 b$ & & \\
\hline$A B_{3}$ & $a d a^{\prime} d$ & 15 & $m C 32$ & $208 ; 3 \mathrm{c}$ & & \\
\hline
\end{tabular}


Table 4 (continued)

\begin{tabular}{lllllll}
\hline$A_{x} B_{y} C_{z}$ & & $\mathrm{SG}$ & $\mathrm{PS}$ & $T_{i}(A / B / C)$ & $\mathrm{NaCl}_{\text {derivative }}$ & ZnS derivative \\
\hline$A B_{3}$ & $a d$ & 13 & $m P 8$ & $208 ; 3 \mathrm{e}$ & $\mathrm{ZrCl}_{4}$ & \\
$A B_{3}$ & $c c^{\prime}$ & 69 & $o F 32$ & $126 ; 3$ & & $\mathrm{Nb}_{4} \mathrm{~N}_{3}, \mathrm{SnF}_{4}$ \\
$\mathrm{TiAl}_{3}$ & $c$ & 139 & $t I 8$ & $048 ; 3$ & $\mathrm{SbCu}_{3} \mathrm{~S}_{4}$ \\
$A B_{4}$ & $c^{\prime} d c^{\prime} d^{\prime}$ & 70 & $o F 40$ & $106 ; 4 \mathrm{c}$ & \\
$A B_{4}$ & $c^{\prime} d$ & 12 & $m C 20$ & $106 ; 4 \mathrm{~d}$ & $\mathrm{~K}_{4} \mathrm{UO}_{5}$ & \\
$A B_{4}$ & $c d c d^{\prime}$ & 70 & $o F 80$ & $028 ; 4 \mathrm{~b}$ & $\mathrm{M}_{4} \mathrm{UO}_{5}$ \\
$A B_{4}$ & $d c$ & 15 & $m C 20$ & $028 ; 4 \mathrm{c}$ & $\mathrm{Lu}_{5} \mathrm{~S}_{6}$ \\
$A B_{5}$ & $d d^{\prime}$ & 70 & $o F 48$ & $008 ; 5 \mathrm{a}$ & $\mathrm{V}_{6} \mathrm{C}_{5}(\mathrm{I}), \mathrm{Sc}_{5} \mathrm{~S}_{6}$ \\
$A B_{5}$ & $d$ & 12 & $m C 12$ & $008 ; 5 \mathrm{e}$ & $\beta-\mathrm{Li}_{6} \mathrm{UO}_{6}$
\end{tabular}

[210] structural units $e-i$ of Forsyth \& Gran (1962) family [Fig. 3A(b), deposited]

\begin{tabular}{|c|c|c|c|c|c|c|}
\hline $\mathrm{UPb}$ & $e g$ & 141 & $t I 8$ & $4416 ; 1$ & $\mathrm{Pd}_{2} \mathrm{D}, \mathrm{Ti}_{2} \mathrm{~N}$ & $\mathrm{CuFeS}_{2}, \alpha-\mathrm{ZnCl}_{2}$ \\
\hline $\mathrm{CuAu}$ & $f$ & 123 & $t P 2$ & $468 ; 1$ & & $(\mathrm{Ga}, \mathrm{As})(\mathrm{Al}, \mathrm{As})$ \\
\hline $\mathrm{NaHg}$ & $f$ & 63 & $o C 16$ & $468 ; 1$ & & \\
\hline$A_{2} B_{3}$ & eh & 12 & $m C 10$ & $3312 ; 1.5$ & & \\
\hline $\mathrm{MoPt}_{2}$ & $e f, g$ & 71 & oI6 & $2212 ; 2 \mathrm{a}$ & $\square \mathrm{Ti}_{2} \square \mathrm{O}_{2}$ & $\mathrm{GeCu}_{2} \mathrm{Se}_{3}$ \\
\hline$A B_{2}$ & $f h$ & 12 & $m C 12$ & $246 ; 2$ & & \\
\hline$A B_{2}$ & $e i$ & 12 & $m C 12$ & $328 ; 2$ & & \\
\hline $\mathrm{Mn}_{2} \mathrm{Au}_{5}$ & $g h$ & 12 & $m C 14$ & $1310 ; 2.5$ & & $\mathrm{NiSi}_{2} \mathrm{Cu}_{4} \mathrm{~S}_{7}$ \\
\hline$A_{2} B_{5}$ & $f i$ & 12 & $m C 14$ & $236 ; 2.5$ & & \\
\hline $\mathrm{Mo}_{3} \mathrm{Al}_{8}$ & $g h_{2}$ & 12 & $m C 22$ & $0.73 .39 .3 ; 2.7$ & & \\
\hline$A B_{3}$ & $g i$ & 12 & $m C 16$ & $1210 ; 3$ & & \\
\hline $\mathrm{TiAl}_{3}$ & $h$ & 139 & $t I 8$ & $048 ; 3$ & $\mathrm{Nb}_{4} \mathrm{~N}_{3}, \mathrm{SnF}_{4}$ & $\mathrm{SbCu}_{3} \mathrm{~S}_{4}$ \\
\hline$A_{2} B_{7}$ & $h i$ & 12 & $m C 18$ & $038 ; 3.5$ & & \\
\hline $\mathrm{MoNi}_{4}$ & $i$ & 87 & $t I 10$ & $028 ; 4 a$ & $\begin{array}{l}\mathrm{UF}_{5}, \mathrm{Na}_{4} \mathrm{UO}_{5}, \\
\mathrm{Pd}_{5} \mathrm{D}_{4}, \mathrm{Ti}_{4} \mathrm{O}_{5}\end{array}$ & \\
\hline
\end{tabular}

[001] structural units $u-y$ of Johansson \& Linde (1936) and Brauer (1939) family [Fig. 3A(c) deposited]

\begin{tabular}{|c|c|c|c|c|c|c|}
\hline $\mathrm{UPb}$ & $x y^{\prime} x^{\prime} y$ & 141 & $t I 8$ & $4416 ; 1$ & $\begin{array}{l}\gamma-\mathrm{LiFeO}_{2} \\
\mathrm{Pd}_{2} \mathrm{D}, \mathrm{Ti}_{2} \mathrm{~N}\end{array}$ & $\mathrm{CuFeS}_{2}$ \\
\hline $\mathrm{CuAu}$ II & $y x_{9} y^{\prime} x_{9}^{\prime}$ & 74 & $o I 40$ & $45.69 .6 ; 1$ & & \\
\hline $\mathrm{CuAu}$ & $x$ & 123 & $t P 2$ & $468 ; 1$ & & $(\mathrm{Ga}, \mathrm{As})(\mathrm{Al}, \mathrm{As})$ \\
\hline $\mathrm{NaHg}$ & $x$ & 63 & $o C 16$ & $468 ; 1$ & & \\
\hline $\mathrm{ZrSi}_{2}$ & $u u^{\prime} y^{\prime} v^{\prime} v y$ & 63 & $o C 12$ & $248 ; 2 a$ & & \\
\hline$(\mathrm{Zr}, \mathrm{Al})(\mathrm{Si}, \mathrm{Al})_{2}$ & $\begin{array}{l}u u^{\prime} x^{\prime} v v^{\prime} y^{\prime} \\
u^{\prime} u x v^{\prime} v y\end{array}$ & 141 & $t I 24$ & $248 ; 2 b$ & & \\
\hline $\mathrm{ZrGa}_{2}$ & $v_{2} y u_{2} y$ & 65 & $o C 12$ & $254 ; 2 \mathrm{a}$ & & \\
\hline $\mathrm{HfGa}_{2}$ & $\begin{array}{l}u_{2} y v_{2} x^{\prime} \\
u_{2}^{\prime} y^{\prime} v_{2}^{\prime} x\end{array}$ & 141 & $t I 24$ & $254 ; 2 b$ & & \\
\hline $\mathrm{Nb}_{5} \mathrm{Ga}_{13}$ & $\begin{array}{l}u u_{2}^{\prime} u y v v_{2}^{\prime} v_{2} \\
v_{2}^{\prime} v y u u_{2}^{\prime} u\end{array}$ & 65 & $o C 36$ & $0.848 ; 2.6$ & & \\
\hline $\mathrm{TiAl}_{3}$ & $u_{2} u_{2}^{\prime}$ & 139 & $t I 8$ & $048 ; 3$ & $\mathrm{Nb}_{4} \mathrm{~N}_{3}, \mathrm{SnF}_{4}$ & $\mathrm{SbCu}_{3} \mathrm{~S}_{4}$ \\
\hline $\mathrm{ZrAl}_{3}$ & $v_{4} v_{4}^{\prime}$ & 139 & $t I 16$ & $054 ; 3$ & & \\
\hline $\mathrm{CdAu}_{3} \mathrm{II}$ & $v_{4} v_{4}^{\prime}$ & 107 & $t I 16$ & $054 ; 3$ & & \\
\hline $\mathrm{AuCu}_{3}$ & $u$ & 221 & $c P 4$ & $060 ; 3$ & $\square \mathrm{Nb}_{3} \square \mathrm{O}_{3}$, & $\square \mathrm{CdIn}_{2} \mathrm{Se}_{4}$ \\
\hline $\mathrm{SiU}_{3}$-tetr. & $u$ & 140 & $t I 16$ & $060 ; 3$ & & \\
\hline $\mathrm{SiIr}_{3}$ & $u$ & 140 & $t I 16$ & $060 ; 3$ & & \\
\hline $\mathrm{LT} \mathrm{GaPt}_{3}$ & $u$ & 127 & $t P 16$ & $060 ; 3$ & & \\
\hline $\mathrm{SrPb}_{3}$ & $u$ & 123 & $t P 4$ & $060 ; 3$ & & \\
\hline $\mathrm{CuTi}_{3}$ & $u$ & 123 & $t P 4$ & $060 ; 3$ & & \\
\hline $\mathrm{SiU}_{3}$-orth. & $u$ & 69 & $o F 32$ & $060 ; 3$ & & \\
\hline $\mathrm{GePt}_{3}$ & $u$ & 12 & $m C 16$ & $060 ; 3$ & & \\
\hline $\mathrm{PdAuCu}_{2}$ & $u$ & 123 & $t P 4$ & $060 ; 3 /$ & & \\
\hline & & & & $060 ; 3 /$ & & \\
\hline & & & & $468 ; 1$ & & \\
\hline $\mathrm{ZnAu}_{3}$ & $u$ & 142 & $t I 64$ & $060 ; 3$ & & \\
\hline$(\mathrm{Tl}, \mathrm{Pb}) \mathrm{Pd}_{3}$ & $u$ & 139 & $t I 24$ & $060 ; 3$ & & \\
\hline$\alpha-\mathrm{PdCu}_{3}$ & $u$ & 123 & $t P 28$ & $060 ; 3$ & & \\
\hline$(\mathrm{Pt}, \mathrm{Zn})(\mathrm{Zn}, \mathrm{Cu})_{3}$ & $u$ & 139 & $t I 40$ & $060 ; 3$ & & \\
\hline$(\mathrm{Zn}, \mathrm{Ga}) \mathrm{Au}_{3}$ & $u$ & 140 & $t I 48$ & $060 ; 3$ & & \\
\hline $\mathrm{Ce}_{3} \mathrm{Sn}_{7}$ & $u_{4} y v_{4} y$ & 65 & $o C 20$ & $1.35 .32 .7 ; 2.3$ & & \\
\hline $\mathrm{Gd}_{3} \mathrm{Sn}_{7}$ & $u_{2}^{\prime} u y v$ & 65 & $o C 20$ & $1.348 ; 2.3$ & & \\
\hline & $v_{2}^{\prime} v y u$ & & & & & \\
\hline $\mathrm{Ce}_{2} \mathrm{Sn}_{5}$ & $v_{6}^{\prime} y^{\prime} u_{6}^{\prime} y^{\prime}$ & 65 & $o C 28$ & $15.52 ; 2.5$ & & \\
\hline \multicolumn{7}{|c|}{ Layered (001) structures } \\
\hline $\mathrm{CuAu}$ & $(A B)$ & 123 & $t P 4$ & $468 ; 1$ & & $(\mathrm{Ga}, \mathrm{As})(\mathrm{Al}, \mathrm{As})$ \\
\hline $\mathrm{CuZr}_{2}$ & $\left(A B_{2}\right)$ & 139 & $t I 6$ & $440 ; 2$ & & $(\mathrm{Ga}, \mathrm{As})(\mathrm{Al}, \mathrm{As})_{2}$ \\
\hline TiCd & $\left(A_{2} B_{2}\right)$ & 129 & $t P 4$ & $848 ; 1$ & & $(\mathrm{Ga}, \mathrm{As})_{2}(\mathrm{Al}, \mathrm{As})_{2}$ \\
\hline
\end{tabular}

Hoppe, 1971a), $\quad \beta-\mathrm{Li}_{5} \mathrm{Ga}_{2} \mathrm{O}_{4}$ (Stewner \& Hoppe, 1971b), $\mathrm{Li}_{5} \mathrm{Tl}_{{ }_{2}} \mathrm{O}_{4}$ (Hoppe \& Panek, 1971) or $\mathrm{Na}_{6} \mathrm{~Pb}_{\square} \mathrm{O}_{4}$ (Panek \& Hoppe, 1973).

There were 36 structures with a single environment $T_{i}$ of $A$ and a single environment $T_{i}$ of $B$ atoms $\left(M_{i}=2, \S 2\right)$ obtained in the present investigation (Table $6 a$ ). The structure map of the p.c. lattice (Fig. 6) is similar to the structure map of $\mathrm{CaTiO}_{3}$ related structures (Hauck \& Mika, 1997, 2000a), but different from the structure maps of the square, b.c.c. or f.c.c. lattice (Figs. 2, 4 and 5). The maximum range of the Cowley short-range order parameters $\alpha_{i}(i=1-3)$ is obtained for a tetrahedron with the four structures $0120 ; 1,24$ $8 ; 1,440 ; 1$ and 6128 ; (1) at the corners. A $30 T_{3} ; 1$ structure $\left(\alpha_{1}=0, \alpha_{2}=-1\right)$ for covalent bonding is impossible in the p.c. lattice. The lowest $T_{2}=4$ value is obtained in $\mathrm{Pb} \square \mathrm{O}(440 ; 1)$ and $\mathrm{Pt} \square \mathrm{S}(248 ; 1)$ with $y / x=1$. At $y / x=3, T_{2}=0$ is reached in $\mathrm{Si}_{\square_{3}} \mathrm{~S}_{2}(2 \quad 0 \quad 0 ; 3)$ and $\mathrm{Cu}_{2} \square_{3} \mathrm{O}$ (0 08 ; 3 ). The highest $T_{2}=12$ value in $\mathrm{ZnS}(0120 ; 1)$ indicates a repulsion of $\mathrm{Zn}$ atoms. The s$\mathrm{CN}$ values $T_{1}$ and $T_{2}$ give the numbers of $\mathrm{ZnS}_{4}$ tetrahedra, which are linked by edges and corners, respectively. In the f.c.c. system $T_{1}$ was the number of linked corners; a connection by edges is not allowed in the f.c.c. system (§4). The combination of structural units at the boundary of the structure map was outlined in some detail (Hauck \& Mika, 1997, 2000a).

Most observed structures are within two structure series of (110) layered structures and the ZnS family (Tables $6 b$ and $c$ ). The ZnS (sphalerite) related structures are listed already in Table 4(b) because of the two f.c.c. lattices of $\mathrm{Zn}$ and $\mathrm{S}$ atoms with a translation of $a_{0} / 4, a_{0} / 4$, $a_{0} / 4$. Many structures can be considered as combinations of 
Table 4 (continued)

\begin{tabular}{|c|c|c|c|c|c|c|}
\hline$A_{x} B_{y} C_{z}$ & & SG & PS & $T_{i}(A / B / C)$ & $\mathrm{NaCl}$ derivative & $\mathrm{ZnS}$ derivative \\
\hline \multicolumn{7}{|c|}{ Layered (111) structures } \\
\hline $\mathrm{CuPt}, \mathrm{a}$ & $(A B)$ & 166 & $h R 2$ & 60 12; 1a & $\alpha-\mathrm{NaFeO}_{2}$ & \multirow[t]{3}{*}{$\operatorname{In}(\mathrm{Ga}, \mathrm{Al}) \mathrm{P}_{2}$} \\
\hline $\mathrm{ZnAl}_{2}$ & $\left(A B_{2}\right)$ & 164 & $h P 3$ & $606 ; 2$ & $\mathrm{In}_{2} \mathrm{~S}_{3}$ & \\
\hline$A B$ & $\left(A_{2} B_{2}\right)$ & 166 & $h R 4$ & $9312 ; 1$ & & \\
\hline \multicolumn{7}{|c|}{$\mathrm{CuAu}(\mathrm{CsCl})$ related structures in [001] projection with composition of $\mathrm{Cu} / \mathrm{Au}$ layer } \\
\hline $\mathrm{Ti}_{2} \mathrm{Ga}_{3}$ & $A_{4} B / B_{5}$ & 83 & $t P 10$ & $356 ; 1.5$ & & \\
\hline$A B_{3}$ & $A B / B_{2}$ & 65 & $o C 4$ & $224 ; 3 a$ & & \\
\hline $\mathrm{PdCu}_{4}$ & $A_{2} B_{3} / B_{5}$ & 84 & $t P 20$ & $114 ; 4$ & & \\
\hline \multirow[t]{2}{*}{$\square_{4} \mathrm{Co}_{5} \mathrm{Ge}_{7}$} & $B_{5} C_{3} /$ & 107 & $t I 24$ & $224 ; 3 /$ & & \\
\hline & $A_{4} C_{4}$ & & & $\begin{array}{l}1.64 .83 .2 ; \\
462791\end{array}$ & & \\
\hline
\end{tabular}

$\mathrm{CuPt}(\mathrm{CsCl})$ related structures in [111] projection with composition of $\mathrm{Cu} / \mathrm{Pt}$ layer

$\begin{array}{lllllll}A B_{2} & A_{2} B / B_{3} & 15 & m C 24 & 3010 ; 2 \mathrm{a} & \begin{array}{l}\mathrm{TiCl}_{3}, \\ \beta-\mathrm{Na}_{2} \mathrm{PtO}_{3} \\ B_{5}\end{array} \\ & A B_{2} / B_{3} & 151 & h P 18 & 008 ; 5 \mathrm{f} & \mathrm{V}_{6} \mathrm{C}_{5}(\mathrm{II}), \\ \mathrm{Li}_{5} \mathrm{ReO}_{6} \\ A B_{5} & & & & \\ A B_{5} & A B_{2} / B_{3} & 15 & m C 24 & 008 ; 5 \mathrm{~b} & \mathrm{~V}_{6} \mathrm{C}_{5}(\mathrm{III}) \\ & A B_{2} / B_{3} & 12 & m C 12 & 008 ; 5 \mathrm{e} & \square \mathrm{Sc}_{5} \mathrm{~S}_{6}\end{array}$

Other compounds

\begin{tabular}{lllll}
$A B$ & 59 & $o P 4$ & $6212 ; 1 \mathrm{a}$ & \\
$A B$ & 131 & $t P 8$ & $6212 ; 1 \mathrm{~b}$ & \\
$A B_{2}$ & 151 & $h P 9$ & $2212 ; 2 \mathrm{e}$ & \\
$A B_{3}$ & 63 & $o C 16$ & $224 ; 3 \mathrm{~b}$ & \\
$A B_{3}$ & 15 & $m C 32$ & $208 ; 3 \mathrm{~d}$ & $\mathrm{Ha}_{2} \mathrm{Se}_{3}$ \\
$A B_{4}$ & 14 & $m P 20$ & $107 ; 4 \mathrm{a}$ & $\mathrm{UCl}_{5}$ \\
$A B_{7}$ & 212 & $c P 32$ & $006 ; 7$ & $\mathrm{~V}_{8} \mathrm{C}_{7}$ \\
$\mathrm{~V}_{4} \mathrm{Zn}_{5}$ & 139 & $t I 18$ & $546 ; 1.25$ & \\
$\mathrm{Mn}_{7} \mathrm{Pd}_{9}$ & 139 & $t I 32$ & $3.45 .16 .9 ; 1.3$ & \\
$\mathrm{Zn}_{3} \mathrm{Au}_{5}$ & 72 & $o I 128$ & $2.73 .79 .3 ; 1.7$ & \\
$\mathrm{Ga}_{3} \mathrm{Pt}_{5}$ & 65 & $o C 16$ & $2.74 .75 .3 ; 1.7$ & \\
$\mathrm{Mn}_{11} \mathrm{Pd}_{21}$ & 123 & $t P 32$ & $2.24 .44 .4 ; 1.9$ & \\
$\mathrm{Mn}_{9} \mathrm{Au}_{31}$ & 83 & $t P 40$ & $03.37 .1 ; 3.4$ & \\
$\mathrm{GeCa}_{7}, \mathrm{CuPt}_{7}$ & 225 & $c F 32$ & $00012 ; 7$ & \\
$\mathrm{TiPt}_{8}$ & 139 & $t I 18$ & $020 ; 8$ & \\
\hline
\end{tabular}

\section{Conclusions}

The present paper shows how the architecture of ordered body-centered, face-centered and primitive cubic structures/ compounds can be analyzed using square planes. The crystal structures of $A_{x} B_{y}$ compounds are characterized by the selfcoordination numbers $(\mathrm{s}-\mathrm{CN})$ of the nearest $\left(T_{1}\right)$, next-nearest $\left(T_{2}\right)$ and third-nearest $\left(T_{3}\right)$ neighbors and the composition $y / x$ of the compound. The s-CN values are plotted in $T_{1}, T_{2}$ or $\alpha_{1}, \alpha_{2}$ structure maps where $\alpha_{i}$ are short-range order parameters, which are related to the $T_{i}$ values as outlined in $\S 1$, step (vi). Structures found at the corners of these structure maps (Figs. 2 and 4-6) usually have high symmetry and the same $T_{1} T_{2} T_{3} ; y / x$ values for all $A$ and for all $B$ atoms. These structures can be decomposed into smaller structural units, e.g. $v, v^{\prime}$ and $w^{\prime}$, to construct structures that lie along the edges of the structure map and which can be characterized by sequences of structural units as e.g. $v w^{\prime} v_{2}^{\prime} w^{\prime} v$

Table 5

s-CN values of some homologous series of f.c.c. derivative structures with different $r$ and $k$ values (see text).

\begin{tabular}{llll}
\hline$r^{*}$ & $k$ & $T_{i}(\mathrm{~A})$ & Prototype \\
\hline 2 & 2 & $2212 ; 2 \mathrm{a}$ & $\mathrm{MoPt}_{2}$ \\
2 & 1 & $7418 ; 0.5 \mathrm{a}$ & $\mathrm{Pt}_{2} \mathrm{Mo}$ \\
2 & 0 & $12624 ; 0$ & $\mathrm{Cu}$ \\
3 & 3 & $060 ; 3$ & \\
3 & 2 & $468 ; 1$ & $\mathrm{AuCu}_{3}$ \\
3 & 1 & $8616 ; 0.33$ & $\mathrm{CuCu}_{3} \mathrm{Au}$ \\
3 & 0 & $12624 ; 0$ & $\mathrm{Cu}$ \\
4 & & & \\
4 & 4 & $328 ; 4$ & $\mathrm{MoNi}_{4}$ \\
4 & 3 & $6416 ; 1.5$ & \\
4 & 2 & $9520 ; 0.25$ & $\mathrm{Ni}_{4} \mathrm{Mo}$ \\
4 & 1 & $12624 ; 0$ & $\mathrm{Cu}$ \\
\hline
\end{tabular}

$\mathrm{SbCu}_{3} \mathrm{~S}_{4}\left(\mathrm{TiAl}_{3} \square_{4}\right)$, which is $0004 ; 7 \mathrm{~b}$ in the $\mathrm{CaF}_{2}$ system (Table $6 b$; Hauck \& Mika, 1998a). The f.c.c. lattices of the $\mathrm{Zn}$ or $\mathrm{S}$ atoms in $\mathrm{ZnS}$ or of $\mathrm{Mg}$, $\mathrm{Ag}$, As or vacancies $\square$ in $\mathrm{MgAg} \square \mathrm{As}$ [Fig. 4A(a), deposited (or $\square \mathrm{NZnLi}$ ) can be combined in different ways to obtain the p.c. lattice $\left[\begin{array}{ll}6 & 128 \text {; }\end{array}\right.$ (1)] for $\mathrm{Mg}+\mathrm{Ag}$ or $\square+$ As combinations or the b.c.c. lattice for the $\mathrm{Mg}+\mathrm{Ag}+$ As combination. for the Ruddlesden-Popper phase $\mathrm{Sr}_{2} \mathrm{TiO}_{4}$ with $w_{2}^{\prime}(\mathrm{SrO})$ and $v_{2}$ or $v_{2}^{\prime}\left(\mathrm{CaTiO}_{3}\right)$ as structural units (Hauck \& Mika, 1997, 1998b; Parthé et al., 1993).

We could identify approximately 55 structural units in b.c.c. and $\sim 25$ structural units in f.c.c. alloys. Most of the experimental structures are in six different families of crystal structures, which are named after the pioneers, e.g. the Ruddlesden-Popper phases. The structural units have identical square or in a few cases hexagonal planes which combine in different ways similar to a puzzle to give the different structures.

Most of the observed structures are at the right-hand border of the structure maps with low $T_{1}$. The interactions between $A$ atoms vary continuously from attractive at low $T_{2}$ to repulsive at high $T_{2}$ values for different $A_{x} B_{y}$ structures on the righthand borders of the structure maps. The weakest interactions are found at the intersection with the line between $T_{1}=T_{2}=0$ and $T_{1}^{\max }, T_{2}^{\max }\left(\alpha_{1}=\alpha_{2}\right)$.

Most structures with a single set of $T_{i}(A)$ values in Tables 2(a) and 4(a), and some structures in Table 6(a) are closely related, because they have identical space groups and Pearson symbols, but different distortions $(\$ 4)$. Structures with identical $T_{1}$ values can belong to the same type of homogeneous sphere packing of $A$ atoms (Koch \& Fischer, 1992). The 
density $\rho_{0}=0.74$ of the f.c.c. $\mathrm{Cu}$ structure (type 2) for example is reduced to $\rho / \rho_{0}=$ $x /(x+y)$ in $A_{x} B_{y}$ with vacant $B$ positions. For structures on the left-hand borders of the structure maps containing alternating layers of $A$ and $B$ atoms, the packings of $A$ atoms are not stable if the $B$ atoms are removed. The group-subgroup relations (Bärnighausen, 1980; Müller, 1997), which can be arranged for the b.c.c., f.c.c. and p.c. systems (Tables 2-6 and 1A-3A, deposited), allow few space groups. In some structures with different space groups such as 42 2; 2a (Table 2a), 22 12; 2a (Table 4a) and 22 4; 2a (Table 6a) the projections of the crystal structure in the [111] direction are identical, but different in other directions. The Pearson symbol and sometimes also the space group will change in $\mathrm{NaCl}, \mathrm{ZnS}$ or $\mathrm{CaF}_{2}$ derivative structures, if all atom positions are included, or on vacancy formation. In some cases the structures of $A_{x} B_{y}$ compounds can only be compared with the ordering of e.g. anions in $\mathrm{NaCl}$ or $\mathrm{CaF}_{2}$ derivative structures as e.g. $\square \mathrm{Nb}_{3} \square \mathrm{O}_{3}$ or $\operatorname{Pr}_{7} \square_{2} \mathrm{O}_{12}$, if the location of the cations relative to the vacancies $\square$ is added as additional information.

The position of a compound $A_{x} B_{y}$ in the structure map can be different, as is outlined for the layered [001] and [111] structural series in Figs. 4-6. The formation of layered (001) (Schubert family) and (111) (Zalkin \& Ramsey family) compounds with different compositions of the structural units in the b.c.c. system seems to be the consequence of the fact that most other series of structural units are not at the right-hand border of the structure map, as shown in Figs. 4A(a)(d) (deposited) and 4. In the 0612 ; $1 \mathrm{CsCl}$ structure with an alternation of $\mathrm{Cs}$ and $\mathrm{Cl}$ atoms in the [001] or [111] direction, the Cs atoms are as far apart as possible with no nearest neighbor. A similar situation occurs in the $0120 ; 1$ $\mathrm{ZnS}$ structure of the p.c. lattice (Fig. 6), but not for the $468 ; 1 \mathrm{CuAu}$ structure in the f.c.c. lattice with $T_{1}=4$ nearest $\mathrm{Cu}$ neighbors of $\mathrm{Cu}$ atoms (Fig. 5). Attractive interactions between $A=\mathrm{Na}, \mathrm{Cu}, \square$ (or $B=\mathrm{Tl}, \mathrm{Pt}, \mathrm{S})$ atoms are suggested for 40 12; 1 NaTl (Fig. 4) with the s-CN of 4 nearest and 0 next-nearest neighbors, the homometric $6 \quad 0 \quad 12 ; 1 \mathrm{a}, \mathrm{b} \quad \mathrm{CuPt}$ a,b structures in the f.c.c. system (Fig. 5) and
Table 6

(a) s-CN values of theoretical primitive cubic alloys $A_{x} B_{y}$ with single $T_{i}(A)$ and $T_{i}(B)$ values $\left(M^{i}=2, \S 2\right), T_{i}(A)$ values of square planes perpendicular to the direction of highest symmetry, space group SG ( $A$ and $B$ atoms) and Pearson symbol (PS), No. of reduced cell (Table 3A, deposited) and positions of atoms $A_{2}-A_{8}$.

\begin{tabular}{|c|c|c|c|c|c|c|c|c|}
\hline $\begin{array}{l}T_{i}(A) ; y / x \\
\text { p.c. }\end{array}$ & $\begin{array}{l}T_{i}(A) ; y / x \\
\text { Square }\end{array}$ & SG & PS & No. & $\begin{array}{l}A_{2} \\
A_{6}\end{array}$ & $\begin{array}{l}A_{3} \\
A_{7} \\
\end{array}$ & $\begin{array}{l}A_{4} \\
A_{8}\end{array}$ & $A_{5}$ \\
\hline 612 8; (1) & $444 ;(1)$ & 221 & $c P 1$ & 1 & & & & \\
\hline $584 ; 1$ & 44 4; (1) & 123 & $t P 4$ & 8 & 001 & & & \\
\hline$(464 ; 1 a) \dagger$ & $220 ; 1 \mathrm{a}$ & 51 & $o P 4$ & 9 & $\begin{array}{llll}0 & 0 & 1\end{array}$ & & & \\
\hline$(464 ; 1 b) \dagger$ & $220 ; 1 b$ & 123 & $t P 8$ & 45 & $0 \overline{1} 1$ & 001 & 012 & \\
\hline$(452 ; 1) \dagger$ & $212 ; 1$ & 10 & $m P 8$ & 46 & $0 \overline{1} 2$ & 001 & 002 & \\
\hline $440 ; 1$ & $444 ;(1)$ & 123 & $t P 2$ & 2 & & & & \\
\hline (3 6 4; 1a) & $666 ;(1) \ddagger$ & 166 & $h R 12$ & 12 & 100 & & & \\
\hline (3 $64 ; 1 b)$ & $220 ; 1 \mathrm{a}$ & 63 & $o C 16$ & 54 & $1 \overline{1} \overline{1}$ & 100 & 101 & \\
\hline \multirow[t]{2}{*}{$(364 ; 1 c)$} & $220 ; 1 b$ & 225 & $c F 64$ & 77 & 011 & 101 & 110 & 111 \\
\hline & & & & & 122 & 212 & 221 & \\
\hline \multirow[t]{2}{*}{ (3 $64 ; 1 d)$} & $220 ; 1 b$ & 160 & $h R 48$ & 77 & 011 & 101 & 110 & 111 \\
\hline & & & & & 122 & 212 & 223 & \\
\hline \multirow[t]{2}{*}{$(364 ; 1 e)$} & $220 ; 1 b$ & 141 & $t I 32$ & 77 & 011 & 101 & 110 & 111 \\
\hline & & & & & 122 & 223 & 232 & \\
\hline$(354 ; 1 a)$ & $212 ; 1$ & 2 & $a P 8$ & 58 & 110 & $12 \overline{1}$ & 120 & \\
\hline \multirow[t]{2}{*}{ (3 $54 ; 1 \mathrm{~b})$} & $212 ; 1$ & 5 & $m C 32$ & 76 & $0 \overline{1} 1$ & $0 \overline{1} 2$ & 001 & $1 \overline{1} 1$ \\
\hline & & & & & $1 \overline{1} 2$ & 101 & 111 & \\
\hline \multirow[t]{2}{*}{$(354 ; 1 c)$} & $212 ; 1$ & 2 & $a P 16$ & 76 & $0 \overline{1} 2$ & 002 & 012 & $1 \overline{1} 1$ \\
\hline & & & & & $1 \overline{1} 2$ & 101 & 111 & \\
\hline \multirow[t]{2}{*}{ (3 $54 ; 1 d)$} & $212 ; 1$ & 43 & $o F 64$ & 76 & $0 \overline{1} 1$ & $0 \overline{1} 2$ & 012 & $1 \overline{1} 1$ \\
\hline & & & & & $1 \overline{1} 2$ & 101 & 111 & \\
\hline \multirow[t]{2}{*}{$(354 ; 1 e)$} & $212 ; 1$ & 15 & $m C 32$ & 76 & $0 \overline{1} 2$ & 001 & 002 & $1 \overline{1} 1$ \\
\hline & & & & & $1 \overline{1} 2$ & 101 & 111 & \\
\hline \multirow[t]{2}{*}{ (3 54 ; 1f) } & $212 ; 1$ & 12 & $m C 32$ & 76 & $0 \overline{2} 1$ & 002 & 012 & $1 \overline{1} 1$ \\
\hline & & & & & $1 \overline{1} 2$ & 101 & 111 & \\
\hline $344 ; 1 a$ & $322 ; 1$ & 65 & $o C 8$ & 11 & 001 & & & \\
\hline 34 4; 1b & $204 ; 1$ & 141 & $t I 16$ & 61 & $\begin{array}{llll}0 & 0 & 1\end{array}$ & 010 & 101 & \\
\hline$(264 ; 1 a) \dagger$ & $220 ; 1 \mathrm{a}$ & 63 & $o C 8$ & 15 & $01 \overline{1}$ & & & \\
\hline$(264 ; 1 b) \dagger$ & $220 ; 1 b$ & 139 & $t I 16$ & 62 & 101 & 110 & 211 & \\
\hline$(256 ; 1) \dagger$ & $212 ; 1$ & 12 & $m C 16$ & 57 & $01 \overline{2}$ & $01 \overline{1}$ & $10 \overline{1}$ & \\
\hline $248 ; 1$ & $044 ; 1$ & 123 & $t P 2$ & 3 & & & & \\
\hline $184 ; 1$ & 04 4; 1 & 123 & $t P 4$ & 14 & $00 \overline{1}$ & & & \\
\hline $0120 ; 1$ & $044 ; 1$ & 225 & $c F 8$ & 4 & & & & \\
\hline$(244 ; 1.3 a) \dagger$ & $222 ; 1.3 \ddagger$ & 146 & $h R 21$ & 40 & 010 & 110 & & \\
\hline$(244 ; 1.3 b) \dagger$ & $222 ; 1.3 \ddagger$ & 2 & $a P 7$ & 40 & $11 \overline{1}$ & 110 & & \\
\hline 33 2; 1.5; & $111 ; 1.5$ & 10 & $m P 5$ & 19 & 001 & & & \\
\hline 44 0; 2 & $202 ; 2$ & 123 & $t P 3$ & 5 & & & & \\
\hline $224 ; 2 \mathrm{a}$ & $020 ; 2$ & 51 & $o P 3$ & 6 & & & & \\
\hline $224 ; 2 b$ & $060 ; 2 \ddagger$ & 151 & $h P 9$ & 75 & 010 & 110 & & \\
\hline $222 ; 2$ & $060 ; 2 末$ & 2 & $a P 9$ & 74 & $11 \overline{2}$ & $12 \overline{2}$ & & \\
\hline $062 ; 2$ & $666 ;(1) \ddagger$ & 164 & $h P 3$ & 7 & & & & \\
\hline$(123 ; 2.5) \dagger$ & $111 ; 2.5 \ddagger$ & 2 & $a P 7$ & 40 & 010 & & & \\
\hline $008 ; 3$ & $004 ; 3$ & 229 & $c I 8$ & 16 & & & & \\
\hline $200 ; 4$ & $0004 ; 4$ & 83 & $t P 5$ & 19 & & & & \\
\hline $002 ; 6$ & $0006 ; 6$ & 148 & $h R 21$ & 40 & & & & \\
\hline
\end{tabular}

$\dagger$ On the borders of the $T_{1} T_{2} T_{3} ; y / x$ polyhedron. $\ddagger$ Hexagonal planar.

(b) Different series of structures and $T_{i}(\square)$ values of $M_{x} \square_{y} \mathrm{O}_{z}$ or $\mathrm{CaF}_{2}$ derivative structures with a sequence of layers such as $A=\square, B=\mathrm{O}$ in $\mathrm{Pb} \square \mathrm{O}$ structure, space group SG and Pearson symbol PS for all atoms without vacancy position $\square$ (Fig. 4A, deposited).

\begin{tabular}{|c|c|c|c|c|}
\hline \multicolumn{2}{|l|}{$M_{x} \square_{y} \mathrm{O}_{z}$} & SG & PS & $T_{i}(\square)$ \\
\hline \multicolumn{2}{|l|}{$\mathrm{CaF}_{2}$} & 225 & $c F 12$ & $6128 ;(1)$ \\
\hline \multicolumn{2}{|c|}{$\mathrm{EuOF}$} & 166 & $h R 9$ & $6128 ;(1)$ \\
\hline \multicolumn{2}{|c|}{$\begin{array}{l}\gamma \text {-LaOF, } \mathrm{ZrH}_{2} \\
\mathrm{SiPt}_{2}\end{array}$} & 123 & $t P 12$ & $6128 ;(1)$ \\
\hline \multicolumn{5}{|c|}{ Layered (001) structures } \\
\hline $\mathrm{Pb} \square \mathrm{O}$ & $A B$ & 129 & $t P 4$ & $440 ; 1$ \\
\hline$M_{3} \square_{2} \mathrm{O}_{4}$ & $A B_{2}$ & 139 & $t I 14$ & $440 ; 2$ \\
\hline$M_{2} \square \mathrm{O}_{3}$ & $A B_{3}$ & 129 & $t P 10$ & $440 ; 3$ \\
\hline $\mathrm{M} \square \mathrm{O}$ & $A_{2} B_{2}$ & 123 & $t P 8$ & $584 ; 1$ \\
\hline$M_{3} \square_{2} \mathrm{O}_{4}$ & $A B A B_{3}$ & 129 & $t P 14$ & $440 ; 2$ \\
\hline $\mathrm{M} \square \mathrm{O}$ & $A B A_{2} B_{2}$ & 99 & $t P 12$ & $4.76 .72 .7 ; 1$ \\
\hline
\end{tabular}


Table 6 (continued)

\begin{tabular}{|c|c|c|c|c|}
\hline$M_{x} \square_{y} \mathrm{O}_{z}$ & & SG & PS & $T_{i}(\square)$ \\
\hline \multicolumn{5}{|c|}{ Layered (111) structures } \\
\hline $\mathrm{M} \square \mathrm{O}$ & $A B$ & 160 & $h R 6$ & $484 ; 1$ \\
\hline$M_{3} \square_{2} \mathrm{O}_{4}$ & $A B_{2}$ & 164 & $h P 7$ & $062 ; 2$ \\
\hline$M_{2} \square \mathrm{O}_{3}$ & $A B_{3}$ & 160 & $h R 15$ & $080 ; 3$ \\
\hline$M \square \mathrm{O}$ & $A_{2} B_{2}$ & 166 & $h R 12$ & $364 ; 1 \mathrm{a}$ \\
\hline$M_{3} \square_{2} \mathrm{O}_{4}$ & $A B A B_{3}$ & 156 & $h P 7$ & $363 ; 2$ \\
\hline$M \square \mathrm{O}$ & $A B A_{2} B_{2}$ & 156 & $h P 6$ & $283.3 ; 1$ \\
\hline \multicolumn{5}{|c|}{$\begin{array}{l}\text { Layered (110) structures with different composition } A=M \mathrm{O}_{2}, A^{\prime}=M_{3} \mathrm{O}_{6}, \\
A^{\prime \prime}=M_{4} \mathrm{O}_{8}, B=M \square_{2}, C=M \square \mathrm{O}, D=M_{3} \square \mathrm{O}_{5}, E=M_{4} \square \mathrm{O}_{7}, F=M_{7} \square_{2} \mathrm{O}_{12}, \\
G=M_{11} \square_{2} \mathrm{O}_{20} \text { (Thornber \& Bevan, 1970) }\end{array}$} \\
\hline $\mathrm{Pt} \square \mathrm{S}$ & $A B$ & 131 & $t P 4$ & $248 ; 1$ \\
\hline$M_{3} \square_{2} \mathrm{O}_{4}$ & $A B_{2}$ & 65 & $o C 6$ & $224 ; 2 \mathrm{a}$ \\
\hline$M_{2} \square \mathrm{O}_{3}$ & $A B_{3}$ & 47 & $o P 4$ & $224 ; 3$ \\
\hline$M \square \mathrm{O}$ & $A_{2} B_{2}$ & 51 & $o P 4$ & $464 ; 1 \mathrm{a}$ \\
\hline$M_{3} \square_{2} \mathrm{O}_{4}$ & $A B A B_{3}$ & 47 & $o P 6$ & $236 ; 2$ \\
\hline$M \square \mathrm{O}$ & $A B A_{2} B_{2}$ & 25 & $o P 6$ & $3.35 .35 .3 ; 1$ \\
\hline $\mathrm{Cu}_{2} \square_{3} \mathrm{O}$ & $B C$ & $224 / 201$ & $c P 6$ & $008 ; 3$ \\
\hline $\mathrm{Pr}_{7} \square_{2} \mathrm{O}_{12}$ & $F$ & 148 & $h R 57$ & $002 ; 6$ \\
\hline $\mathrm{Pr}_{9} \square_{2} \mathrm{O}_{16}$ & $A^{\prime} D_{2}$ & 2 & $a P 25$ & $001 ; 8$ \\
\hline$\left(\mathrm{Ce}_{21} \square_{4} \mathrm{O}_{38}\right)$ & $A^{\prime} D A^{\prime} D_{2} A^{\prime} D$ & & & \\
\hline$\left(\mathrm{Ce}_{19} \square_{4} \mathrm{O}_{34}\right)$ & $\begin{array}{l}A^{\prime} D\left(A^{\prime} D_{2}\right)_{3} A^{\prime} D\left(A^{\prime} D_{2}\right)_{2} \\
\text { or } A^{\prime \prime} E_{5} A^{\prime \prime} E_{6} A^{\prime \prime} E_{5}\end{array}$ & & & \\
\hline $\operatorname{Pr}_{10} \square_{2} \mathrm{O}_{18}$ & $A^{\prime \prime} E_{4}$ & 11 & $m P 112$ & $001 ; 9$ \\
\hline $\operatorname{Pr}_{12} \square_{2} \mathrm{O}_{22}$ & $A^{\prime \prime} E_{2}$ & 11 & $m P 68$ & $\begin{array}{lllll}0 & 0 & 0 & 0 & 3 ;\end{array} 11$ \\
\hline $\mathrm{Tb}_{11} \square_{2} \mathrm{O}_{20}$ & $G$ & 2 & $a P 31$ & $00004 ; 10$ \\
\hline
\end{tabular}

(c) ZnS family and other $A_{x} B_{y} C_{z}$ structures with $T_{i}(A / B)$

\begin{tabular}{|c|c|c|c|}
\hline$A_{x} B_{y} C_{z}$ & SG & PS & $T_{i}(A / B)$ \\
\hline \multicolumn{4}{|l|}{ ZnS family } \\
\hline $\mathrm{Zn} \square \mathrm{S}$ & 216 & $c F 8$ & $0120 ; 1$ \\
\hline $\operatorname{MgAg} \square \mathrm{As}$ & 216 & $c F 12$ & $0120 ; 1$ \\
\hline$\square \mathrm{NZnLi}$ & 216 & $c F 12$ & $0120 ; 1$ \\
\hline$\square \mathrm{CdIn}_{2} \mathrm{Se}_{4}$ & 111 & $t P 7$ & $000 ; 7 \mathrm{a}$ \\
\hline $\mathrm{SbCu}_{3} \mathrm{~S}_{4}$ & 121 & $t I 16$ & $000 ; 7 \mathrm{~b}$ \\
\hline $\mathrm{CuFeS}_{2}$ & 122 & $t I 16$ & $040 ; 3 b$ \\
\hline$\alpha-\mathrm{Zn} \square_{3} \mathrm{Cl}_{2}$ & 122 & $t I 12$ & 04 0; 3b \\
\hline$(\mathrm{Ga}, \mathrm{As})(\mathrm{Al}, \mathrm{As})$ & 115 & $t P 4$ & $040 ; 3 \mathrm{c}$ \\
\hline $\mathrm{In}(\mathrm{Ga}, \mathrm{Al}) \mathrm{P}_{2}$ & 160 & $h R 4$ & $060 ; 3$ \\
\hline $\mathrm{GeCu}_{2} \mathrm{Se}_{3}$ & 44 & $o I 12$ & $020 ; 5 a$ \\
\hline$\beta$ - $\square \mathrm{Ga}_{2} \mathrm{Se}_{3}$ & 9 & $m C 20$ & $020 ; 5 \mathrm{e}$ \\
\hline $\mathrm{NiSi}_{2} \mathrm{Cu}_{4} \mathrm{~S}_{7}$ & 5 & $m C 28$ & $010 ; 6$ \\
\hline$(\mathrm{Ga}, \mathrm{As})_{2}(\mathrm{Al}, \mathrm{As})_{2}$ & 115 & $t P 8$ & $080 ; 3$ \\
\hline$(\mathrm{Ga}, \mathrm{As})(\mathrm{Al}, \mathrm{As})_{2}$ & 119 & $t I 12$ & $040 ; 5$ \\
\hline \multicolumn{4}{|l|}{ Other compounds } \\
\hline $\mathrm{Si}_{{ }_{3}} \mathrm{~S}_{2}$ & 72 & $o I 12$ & $200 ; 3$ \\
\hline $\mathrm{Li}_{3} \mathrm{AlN}_{2}$ & 206 & $c I 96$ & $032 ; 3$ \\
\hline$(\mathrm{Fe}, \mathrm{Mn})_{2} \square \mathrm{O}_{3}$ & 206 & cI80 & $032 ; 3$ \\
\hline $\mathrm{Hg}_{\square_{3}} \mathrm{I}_{2}$ & 137 & $t P 12$ & $040 ; 3 \mathrm{a}$ \\
\hline $\mathrm{Sn} \square_{7} \mathrm{I}_{4}$ & 205 & $c P 40$ & 00 1; 7 \\
\hline $\mathrm{Li}_{7} \mathrm{VN}_{4}$ & 218 & $c P 96$ & 000 1.5; 7 \\
\hline \multirow[t]{2}{*}{$\beta-\mathrm{Li}_{5} \mathrm{Al} \square_{2} \mathrm{O}_{4}$} & 59 & $o P 20$ & $\begin{array}{llll}0 & 0 & 0 & 2 ;\end{array}$ \\
\hline & & & 022 ; 3 \\
\hline \multirow[t]{2}{*}{$\beta-\mathrm{Li}_{5} \mathrm{Ga}_{2} \mathrm{O}_{4}$} & 21 & $o C 40$ & $00002 ; 7 /$ \\
\hline & & & $0086 ; 3$ \\
\hline \multirow[t]{2}{*}{$\mathrm{Li}_{5} \mathrm{Tl}_{{ }_{2}} \mathrm{O}_{4}$} & 137 & $t P 80$ & $0004 ; 7 /$ \\
\hline & & & $050 ; 3$ \\
\hline $\mathrm{Na}_{6} \mathrm{~Pb} \square \mathrm{O}_{4}$ & 217 & $c I 88$ & 030 0; $7(\mathrm{~Pb}, \square)$ \\
\hline
\end{tabular}

$\mathrm{Cu}_{3} \mathrm{Au}(8 \quad 6$ 16; 0.3), Cu [12 6 24; (1)] with $T_{1}=0,4,8,12, T_{2}=6$ and $T_{3}=0,8$, 16, 24 (Table 5) and identical $\alpha_{i}$ values. In quasi-homologous series of structures (different $\alpha_{i}$ values) the different combinations of the $0012 ; 3$ structure of $\mathrm{Sn}, \mathrm{Mg}, \mathrm{Li}$ and $\mathrm{Pd}$ atoms in $\mathrm{SnMgLiPd}$ give rise to the $\mathrm{AgSbLi}{ }_{2}, \mathrm{AlMnCu}_{2}$ and $\mathrm{NaTl}$ structures [Table 2b, Fig. 2A $(a)$ deposited] with different $\alpha_{i}$ values.

A similar situation occurs for magnetic structures (Oleś et al., 1976) with an ordering of two spin directions $\oplus$ and $\ominus$ at $\mathrm{Mn}$ atoms in $\mathrm{MnS}_{2}$ or $\mathrm{MnTe}_{2}$, where the ordering for example follows the $\mathrm{UPb}_{4}$ type $(4416 ; 1)$ or the $\mathrm{CuAu}_{4}$ type (4 68 ; 1 ) structures and $\mathrm{MnSe}_{2}$ has a structure with intermediate $T_{i}$ values $44.713 .3 ; 1$. The four spin directions of the Dy atoms in $\mathrm{DyAlO}_{3}$ are combined in the same way as the four atoms in a quaternary alloy such as SnMgLiPd (Hauck \& Mika, 2000c). The ordering of magnetic moments in the same structures as the ordering of metal atoms in alloys supports a different view of sphere packing, which has been discussed for many centuries (Brunner, 1971), e.g. the statement of Boscovich (1758): 'Atoms are centres of interactions whose diameters are negligible or of minor interest as compared to their separations'.

The principle of filling sites in a given structure is similar to the way we obtained the different structures. We determined the reduced unit cells with single occupation (Tables 1A-3A deposited) and obtained all structures of the structure maps by occupation of other positions. The observed structures of the homologous and quasi-homologous series are a small selection, where $\alpha_{i}$ values do not change or change only along the boundary of the structure map, respectively. These structures with maximum attractive or repulsive interactions between $A$ (or $B$ ) atoms are stabilized by enthalpy. the 24 8; 1 Pt $\square$ S structure (Fig. 4A, deposited) in the p.c. system.

Two other principles of structure formation besides the combinations of structural units were observed in the present investigation: A stepwise filling of atom positions in homologous structures such as $\mathrm{AuCu}_{3}(060 ; 3), \mathrm{AuCu}(468 ; 1)$,
We acknowledge the support of K. Bickmann and D. Henkel, IFF with the preparation of the figures and the text.

\section{References}

Allen, S. M. \& Cahn, J. W. (1972). Acta Metall. 20, 423-433. 
Bärnighausen, H. (1980). MATCH, Commun. Math. Chem. 9, 139175.

Brauer, G. (1939). Z. Anorg. Allg. Chem. 242, 1-22.

Brunner, G. O. (1971). Acta Cryst. A27, 388-390.

Burdett, J. K. (1995). Chemical Bonding in Solids. Oxford University Press.

Chattopadhyay, K., Lele, S., Thangaraj, N. \& Ranganathan, S. (1987). Acta Metall. 35, 727-733.

Donohue, J. (1974). The Structures of the Elements. New York: John Wiley.

Ducastelle, F. (1991). Cohesion and Structure, Vol. 3, Order and Phase Stability in Alloys, edited by F. R. de Boer and D. G. Pettifor. Amsterdam: North-Holland.

Finel, A. \& Ducastelle, F. (1984). Mater. Res. Soc. Symp. Proc. 21, 293-298.

Forsyth, J. B. \& Gran, G. (1962). Acta Cryst. 15, 100-104.

Galasso, F. S. (1970). Structure and Properties of Inorganic Solids. Oxford: Pergamon Press.

Hauck, J. (1980). Acta Cryst. A36, 228-237.

Hauck, J., Henkel, D., Klein, M. \& Mika, K. (1999). J. Solid State Chem. 145, 150-158.

Hauck, J., Henkel, D. \& Mika, K. (1988a). Physica C, 153-155, $1173-$ 1174.

Hauck, J., Henkel, D. \& Mika, K. (1988b). Z. Phys. B, 71, 187-192.

Hauck, J., Henkel, D. \& Mika, K. (1988c). Z. Kristallogr. 182, 124 127.

Hauck, J., Henkel, D. \& Mika, K. (1988d). Z. Kristallogr. 182, 297 306.

Hauck, J., Henkel, D. \& Mika, K. (1989). Int. J. Mod. Phys. B, 3, 14251433.

Hauck, J. \& Mika, K. (1993). Int. J. Mod. Phys. B, 7, 3423-3433.

Hauck, J. \& Mika, K. (1994). Intermetallic Compounds, Vol. 1, Principles, edited by J. H. Westbrook and R. L. Fleischer, pp. 277307. London: Wiley.

Hauck, J. \& Mika, K. (1997). Studies of High Temperature Superconductors, Vol. 25, edited by A. V. Narlikar, pp. 1-74. Commack New York: Nova Science.

Hauck, J. \& Mika, K. (1998a). J. Solid State Chem. 138, 334-341.

Hauck, J. \& Mika, K. (1998b). Supercond. Sci. Technol. 11, 614-630.

Hauck, J. \& Mika, K. (2000a). Solid State Ion. 127, 1-21.

Hauck, J. \& Mika, K. (2000b). Surface Rev. Lett. In the press.

Hauck, J. \& Mika, K. (2000c). J. Magn. Magn. Mater. 212, 389-400.

Ho, S.-M. \& Douglas, B. E. (1968). J. Chem. Educ. 45, 474-476.

Hoppe, R. \& Panek, P. (1971). Z. Anorg. Allg. Chem. 381, 129-139.

Hyde, B. G. \& Andersson, S. (1989). Inorganic Crystal Structures. New York: Wiley.

Johansson, C. H. \& Linde, J. O. (1936). Ann. Physik, 25, 1-48.

Juza, R., Gieren, W. \& Haug, J. (1959). Z. Anorg. Allg. Chem. 300, 6171.

Kanamori, J. \& Kakehashi, Y. (1977). J. Phys. Colloque 7, 274-279.

Ketelaar, J. A. A. (1935). Z. Kristallogr. A, 90, 237-255.

Ketelaar, J. A. A., MacGillavry, C. H. \& Renes, P. A. (1947). Rec. Trav. Chim. Pays-Bas, 66, 501-512.

Koch, E. \& Fischer, W. (1992). International Tables for Crystallography, edited by A. J. C. Wilson, Vol. C, pp. 654-659. Dordrecht: Kluwer Academic Publishers.

Kripyakevich, P. I. \& Grin, Yu. N. (1979). Sov. Phys. Crystallogr. 24, $41-44$.

Křivý, I. \& Gruber, B. (1976). Acta Cryst. A32, 297-298.

MacLaren, J. M., Pendry, J. B., Rous, P. J., Saldin, D. K., Somorjai, G. A., Van Hove, M. A. \& Vvedensky, D. D. (1987). Surface Crystallographic Information Service: A Handbook of Surface Structures. Dordrecht: Reidel.
Mika, K., Hauck, J. \& Funk-Kath, U. (1994). J. Appl. Cryst. 27, 1052 1055.

Mika, K., Henkel, D. \& Hauck, J. (1989). Z. Kristallogr. 186 202-204.

Müller, U. (1991). Anorganische Strukturchemie. Stuttgart: Teubner. Müller, U. (1997). Predictability of Crystal Structures of Inorganic Solids, edited by H. Burzlaff, pp. 74-81. Hünfeld 27.10-30.10. To be published.

Oleś, A., Kajzar, F., Kucab, M. \& Sikora, W. (1976). Magnetic Structures by Neutron Diffraction. Warszawa: Państwowe Wydawnictwo Nakowe.

Panek, P. \& Hoppe, R. (1973). Z. Anorg. Allg. Chem. 400, 208-218.

Pani, M. \& Fornasini, M. L. (1990). Z. Kristallogr. 190, 127-133.

Parthé, E., Gelato, L., Chabot, B., Penzo, M., Cenzual, K. \& Gladyshevskii, R. (1993). TYPIX: Standardized Data and Crystal Chemical Characterization of Inorganic Structure Types, Vol. 1, Gmelin Handbook of Inorganic and Organometallic Chemistry. Berlin: Springer.

Pauling, L. (1929). J. Am. Chem. Soc. 51, 1010-1026.

Pauling, L. (1960). The Nature of the Chemical Bond. Ithaca, New York: Cornell University Press.

Pearson, W. B. (1972). The Crystal Chemistry and Physics of Metals and Alloys. New York: Wiley.

Sanchez, J. M. \& de Fontaine, D. (1981). Structure and Bonding in Crystals, Vol. II, edited by M. O'Keeffe and A. Navrotsky, pp. 117132. New York: Academic Press.

Sato, H. \& Toth, R. S. (1965). Metallur. Soc. Conf. 29, 295-419.

Schubert, K. (1964). Kristallstrukturen zweikomponentiger Phasen. Berlin: Springer.

Schubert, K., Anantharaman, T. R., Ata, H. O. K., Meissner, H. G., Pötzschke, M., Rossteutscher, W. \& Stolz, E. (1960). Die Naturwiss. 47, 512 .

Schubert, K., Meissner, H. G. \& Rossteutscher, W. (1964). Die Naturwiss. 51, 507.

Schweda, E., Bevan, D. J. M. \& Eyring, L. (1991). J. Solid State Chem. 90, 109-125.

Sohncke, L. (1879). Entwicklung einer Theorie der Kristallstruktur, p. 23. Leipzig: B. G. Teubner.

Stewner, F. \& Hoppe, R. (1971a). Z. Anorg. Allg. Chem. 381, 140-148.

Stewner, F. \& Hoppe, R. (1971b). Z. Anorg. Allg. Chem. 381, 149-160.

Teuho, J., Mäki, J. \& Hiraga, K. (1987). Acta Metall. 35, 721-725.

Thornber, M. R. \& Bevan, D. J. M. (1970). J. Solid State Chem. 1, 536544

Villars, P. \& Calvert, L. D. (1986). Pearson's Handbook of Crystallographic Data for Intermetallic Phases, Vols. 1-3. Metals Park, OH: American Society for Metals.

Wiener, C. (1863). Die Grundzüge der Weltordnung. I: Atomlehre, p. 82. Leipzig und Heidelberg: Winter.

Wyckoff, R. W. G. (1982). Crystal Structures, Vols. 1-3. Krieger: Malabar, FL.

Zalkin, A. \& Ramsey, W. J. (1956). J. Phys. Chem. 60, 234-236.

Zalkin, A., Ramsey, W. J. \& Templeton, D. H. (1956). J. Phys. Chem. 60, 1275-1277.

Zhang, J., Von Dreele, R. B. \& Eyring, L. (1993). J. Solid State Chem. 104, 21-32.

Zhang, J., Von Dreele, R. B. \& Eyring, L. (1995a). J. Solid State Chem. 118, 133-140.

Zhang, J., Von Dreele, R. B. \& Eyring, L. (1995b). J. Solid State Chem. 118, 141-147.

Zhang, J., Von Dreele, R. B. \& Eyring, L. (1996). J. Solid State Chem. 122, 53-58. 